\title{
DESIGNING PERFORMANCE: THE SEMI-AuTONOMOUS REVENUE AUTHORITY MODEL IN AFRICA AND LATIN AMERICA*
}

\author{
Robert Taliercio, Jr. \\ East Asia PREM \\ The World Bank \\ rtaliercio@worldbank.org
}

\section{World Bank Policy Research Working Paper 3423, October 2004}

The Policy Research Working Paper Series disseminates the findings of work in progress to encourage the exchange of ideas about development issues. An objective of the series is to get the findings out quickly, even if the presentations are less than fully polished. The papers carry the names of the authors and should be cited accordingly. The findings, interpretations, and conclusions expressed in this paper are entirely those of the authors. They do not necessarily represent the view of the World Bank, its Executive Directors, or the countries they represent. Policy Research Working Papers are available online at http://econ.worldbank.org.

\footnotetext{
* I am grateful to Merilee Grindle, Bob Bates, Glenn Jenkins, and Yasuhiko Matsuda for helpful comments on earlier incarnations of this work, and Michael Engelschalk, Carlos Silvani, and Anna Hansson for comments on an earlier version of this paper. I would like to extend special thanks to the many Latin American and African tax administrators who gave generously of their time and talents, including Superintendents Luis Alberto Arias and Adrian Revilla in Perú, Superintendent Jose Ignacio Moreno León in Venezuela, Commissioner General John Msafari in Kenya, Secretary Franciso Gil Díaz in Mexico, Commissioners Trevor van Heerden and Pravin Gordhan in South Africa, and Commissioner General Annebrit M. Aslund Ericson in Uganda. In addition I would like to thank the many government officials who contributed to this work, including: Mr. Daniel Alvarez, Mr. Fernando Cossío, Mr. Javier Galindo, Mr. Keith Kenneth, Mr. Victor Mejías, Ms. Karen Nginda, Mr. Agweru-Opila, and Ms. Karin Ward. I also extend my gratitude to the US Department of Education for funding through a Fulbright-Hays Doctoral Dissertation Research Award, the David Rockefeller Center for Latin American Studies at Harvard University, and the Tax Policy and Administration Thematic Group of the World Bank.
} 


\section{INTRODUCTION ${ }^{1}$}

During the past decade or so diverse countries have introduced radical reforms in the way their fiscal bureaucracies conduct one of the most pressing national tasks: the collection of taxes (Jenkins, 1994; Taliercio, 2000). The reform, an early version of which originated in the developing world in Bolivia and Ghana in the late 1980s, has now been adopted by more than fifteen countries, including Malaysia, New Zealand, Singapore, Ghana, Kenya, Malawi, Rwanda, South Africa, Tanzania, Uganda, Zambia, Bolivia, Ecuador, Guatemala, Guyana, Mexico, Peru, and Venezuela. ${ }^{2}$ More precisely, there is a pattern in each of these countries in that the traditional line departments (sometimes including customs) are being separated from the ministry of finance (MOF) and granted the legal status of semi-autonomous authorities. ${ }^{3}$ These semi-autonomous revenue authorities (ARAs) are designed with a number of autonomy-enhancing features, including self-financing mechanisms, boards of directors with high ranking public and private sector representatives, and sui generis personnel systems.

The success of the first wave of reforms, in which the ARA model, bolstered by good tax policy reforms, boosted revenues significantly and improved service delivery, has encouraged imitation. The worldwide trend toward semi-autonomous tax authorities has picked up speed recently, as more and more countries adopt this organizational design. In addition, international financial institutions (IFIs) have proposed on an ad hoc basis, though not yet as a matter of formal policy, the adoption of the ARA reform.

Moreover, the ARA reform has coincided with the vogue of autonomization of executive agencies in the OECD and other developed countries. Interestingly, the march toward autonomization in the sphere of fiscal administration (not to mention the phenomenon of autonomization in the sphere of monetary policy through independent central banks) in developing countries began a few years before the launch of executive agencies in Europe and the US, though ideas about New Public Management-type reform were certainly percolating wide and far by the mid-1980s.

\footnotetext{
${ }^{1}$ An earlier and highly condensed version of this work appears in Taliercio (2003a).

${ }^{2}$ In several other countries the reform is under active consideration, including Sri Lanka, Pakistan, and the Philippines, in which a draft ARA reform bill was introduced to Congress in 2002.

${ }^{3}$ Throughout the paper the generic Ministry of Finance (MOF) is used instead of the actual corresponding name in each country.
} 


\section{Central Questions: Theory, Performance, and Design}

In spite of the proliferation of ARAs, there has been little comparative analytical work on their design, performance, or sustainability. ${ }^{4}$ Moreover, there has been no work on the practical side of designing and implementing an ARA reform. This paper attempts to address these gaps in the literature by examining cases of ARA reform from Africa and Latin America. The paper tackles three central questions ${ }^{5}$ :

- First, what has motivated the wave of ARA reforms in Africa, Asia, and Latin America over the past decade?

The paper argues that from a public management perspective autonomy can be used to enhance bureaucratic performance in low capacity public sectors. The argument is simply that in certain cases the benefits of autonomy in terms of organizational performance outweigh the costs. From a normative view, the challenge is determining under what circumstances the net present value of the ARA reform is estimated to be positive. In addressing the question of motivation, the paper seeks to reframe the central question of the debate, which ought to be "Under what circumstances is autonomy appropriate?" rather than "In principle, is autonomy appropriate or not?"

\section{- Second, is there a connection between autonomy and performance?}

Have ARAs actually improved performance, and, if so, how? Focusing on revenue collection, compliance management, taxpayer services, human resource management, and administrative costs, and using quantitative indicators when possible, the cases suggest that autonomy is associated with higher levels of performance. The paper also makes the case that higher levels of autonomy are associated with higher levels of performance.

\footnotetext{
${ }^{4}$ See Jenkins (1994) and Devas et al. (2001). For an early assessment of the African ARAs see Adamolekum and Jah (N.D). On sub-Saharan tax administration reform see Terkper (2003). On South Africa see Hlophe and Friedman (2002). On Peru, see Durand and Thorp (1998) and Durand (2002). On Tanzania see Fjeldstad and Semboja (2001) and Fjeldstad (2002). See also Silvani and Baer (1997) for a useful discussion of tax administration reform strategy.

${ }^{5}$ Two additional questions - one on the political motivation for ARA reform, the other on sustainabilityare treated in Taliercio (2004a and 2004b).
} 
- Third, if there is a connection between autonomy and performance, which specific design features matter most and why?

Autonomy comes in many types and forms (see Verhoest (2004) for a taxonomy of autonomy in public organizations). In spite of the increasing number of countries adopting the ARA reform, there is no consensus on best practice in organizational design. The paper will offer hypotheses based on the cases about why certain designs work better than others and will make specific recommendations for the next generation of ARA reforms.

\section{Methodology and Organization}

The paper analyzes a subset of ARAs from both Africa and Asia. Six cases (the Kenya Revenue Authority, KRA; the Mexican Tax Administration Service, SAT; Peru's National Tax Administration Superintendency, SUNAT; the South African Revenue Service, SARS; the Uganda Revenue Authority, URA; and Venezuela's National Integrated Tax Administration Service, SENIAT) were selected based on three criteria: (1) the importance of the country in the region (measured by GDP in regional comparison), which led to the selection of Mexico and South Africa; (2) the longevity of the reform experience, which led to the inclusion of Uganda, Peru, Venezuela, and Kenya; and (3) the nature of the political context, in which both more (South Africa, Venezuela, Kenya, and Uganda) and less (Mexico and Peru in the mid- to late 1990s) democratic regimes types were selected. Detailed comparative case studies, based on fieldwork carried out in Latin America over an eleven month period in 1998-1999 and in Africa over a three week period in July 2001, were prepared for each of the six countries. The case studies thus refer to this period in the late 1990s and early 2000s.

Section II presents the theoretical arguments for and against ARA reforms in light of both political economy and public management considerations. Section III analyzes ARA performance. Using broad brushstrokes, the section analyzes several general sets of both output and input-based performance indicators: revenue collections, compliance management, and taxpayer services on the output side, and human resources and administrative costs on the input side. Section IV focuses on practical design issues, addressing the following key dimensions of autonomy: legal foundations, corporate 
governance mechanisms, funding mechanisms, personnel management systems, procurement and expenditure management systems, and accountability arrangements. The section moves away from legalistic descriptions of organizational designs to analysis of how these features work in practice, suggesting measures for strengthening ARA design. The paper concludes by offering guidelines for thinking about the conditions under which an ARA might be appropriate.

\section{THE RATIONALE FOR AND AGAINST ARA REFORM}

Generally, autonomy, or self-governance, is defined against the traditional tax administration (that is, a ministerial line department). The extent and nature of ARA autonomy is distinct from the kind of the autonomy assigned to other types of public sector organizations (central banks, for example). In practical terms, how does one think about the nature and level of revenue authority autonomy implied by the political economy and public management literatures? ${ }^{6}$

A useful way to think about autonomy is in terms of the problems it is intended to solve. Autonomy is a response to inadequate central government civil service and public expenditure management (PEM) systems. Autonomy is also considered an antidote to the failure of the political system to build in effective accountability mechanisms that channel political influence around and through the public administration in appropriate, salutary ways. When the political system fails to do these things, undue political influence, which distorts and undermines public service provision, is exerted over public administration. Autonomy is then the vehicle by which the intended outcomecompetent, effective, and fair tax administration - is supposed to be attained.

Viewed through this lens, then, autonomy is intended as a remedy for administrative as well as political problems. On the administrative side there are many cases in which sclerotic civil service systems impede the development of a competent and effective tax administration. Centralized civil services commissions may not recruit the professional, specialized employees that tax agencies need. Moreover, civil service salaries, which may be quite low by private sector standards, are often insufficient for attracting high caliber professionals. This problem no doubt affects the entire

\footnotetext{
${ }^{6}$ For a political economy argument, see Taliercio (2004a).
} 
government, but it is especially acute in the area of tax administration, which requires professional accountants and lawyers with skills easily employed in private sector firms and consulting practices. ${ }^{7}$ In addition, civil service systems are often unable to provide the specialized training needed by tax agencies. All of these problems are made worse by the slow, red tape-laden processes and procedures of typical developing country civil services. So though the problems of a weak civil service affect the whole of government, one can make an argument that those problems are felt much more acutely in the tax administration as compared to most other public agencies. ${ }^{8}$

An additional problem, which, along with low salaries, might be the most pernicious, is characteristic of most African and Latin American cases: the use of the civil service for political patronage purposes. In many countries in Africa and Latin America civil service systems, to the extent that they exist, are only formally meritocratic. They are governed more by the political (and in some African countries, ethnic) calculi of the ruling party than the principles of meritocracy. The patronage problem is exacerbated in the area of fiscal administration because tax administration, especially customs, is viewed as a prime patronage plum and an important source of revenue for political parties. Patronage-based staff appointments lead to the employment of individuals with little or no experience in taxation, corruption, and high turnover rates. An extreme example is the case of Bolivia, in which it was estimated that three-quarters of the staff of the internal revenue agency was replaced after a change of government in 1997 (it was reported that in one case a barber was given a job as a tax auditor). ${ }^{9}$ It is the gravity of the patronage problem in Latin America that led some to view the ARA reform as necessary in order to establish a merit-based system in the area of tax administration. Interestingly, others, especially in Asia, have viewed the ARA reform as necessary for bypassing the inadequacies of the existing civil service. Though different countries have come at the problem from different angles-politicization or calcification of the existing civil service system - the solution is regarded as the same. The promise of autonomy in

\footnotetext{
${ }^{7}$ This problem is compounded by the fact that the opportunity cost of an accountant rises after having served a couple of years in the national tax administration, a situation which promotes the practice of using employment in the tax agency as a training ground for a subsequent private sector career.

${ }^{8}$ The case for unique treatment of the tax administration is based on its unique function as the provider of public resources. Because of that pivotal role, an argument for special treatment has merits.

${ }^{9}$ Taliercio (2000).
} 
the area of personnel management is that of an honest, professional, well-paid staff that is trained on a continuous basis and responsive to management's changing staffing needs over time.

Autonomy is also seen as a remedy for weak corporate governance, in both the administrative and political senses. On the administrative side the idea is to empower a manager to have enough control over personnel, funding, budgeting, and procurement to manage the tax agency effectively and efficiently. Note, however, that each of these dimensions-personnel, funding, budgeting, and procurement-are characterized by separate autonomy-enhancing mechanisms. Even given these separate mechanisms, many ARAs also grant a certain amount of autonomy to the tax agency chief (commissioner or superintendent). The additional autonomy granted to agency management has to do more with the political motivation for reform.

Tax administration has traditionally been an area characterized by high levels of political intervention. Few agencies are as powerful as the tax administration, which monitors and appraises the economic activities of most of the state's citizens and corporations. The tax agency also has important financial information pertaining to the economic operations of each of these actors; nearly all citizens and firms must report to the tax agency at least once a year. The tax administration oversees all sectors of the economy, as opposed to regulatory bodies, which are also powerful but whose reach is much more limited. Thus having political control over the tax agency can pay high dividends. Politicians can intervene in the agency to grant favors such as tax exemptions to supporters or to harass political opponents through audits, for example. The persistent use of the tax agency for political purposes in some countries has eroded taxpayer confidence in the fairness and impartiality of the tax administration in many countries, which, in turn, has undermined compliance. An important aspect of the ARA reform is thus to give the tax agency's management autonomy from undue political influence.

Another central element of the ARA reform is aimed at providing the agency with financial autonomy and stability. The inadequacy of PEM systems in many countrieschronic instability in monthly funding levels and uncertainty about total annual resource allocations - all lead to serious management problems, including the distortion of expenditure efficiency, higher procurement costs, and persistent underfunding. As a 
substitute for a sound PEM system, the ARA reform attempts to provide consistent, predictable funding via a special mechanism, which in many cases means granting the ARA a fixed percentage of collections. In some cases the funds are directly retained by the ARA, thus eliminating dependence on treasury intervention.

It is argued that the percentage-based funding mechanism has two other important benefits. First, once politicians set the maximum cost of collections (in percentage terms) at their preferred level, they are free to leave budget management to the ARA. Second, the mechanism provides incentives to the tax agency to increase collections: as collections increase, the authority's budget increases as well. If the classical assumption that bureaucrats are budget maximizers is valid, then one would expect revenue authority managers and bureaucrats to have solid incentives to do their best to increase collections, thereby increasing their budget (the implications of this mechanism are explored further in the next section). Thus, a percentage-based funding mechanism coupled with automatic retention of funds would not only insulate the ARA from the pernicious effects of a weak PEM system but could also provide hard incentives to increase collections. ${ }^{10}$

Several other features are thought to be important for building autonomy. In order to compensate for slow, cumbersome central procurement processes, ARAs in some cases are empowered to develop their own procurement systems, thereby enhancing managerial effectiveness. Another important autonomy-enhancing feature is the legal foundation of the authority, chiefly its legal status and its right to own property. The legal status of the ARA has the potential to protect it from shifting political winds. In addition authorities that are able to own patrimony have be definition greater flexibility in the utilization of resources. Thus, the organizational features outlined above are intended to grant some measure of autonomy to the tax agency in order to boost its effectiveness, competence, and fairness, and there by its credibility with the taxpayers.

At the same time a number of arguments have been leveled against the idea of ARAs. Some argue against autonomous tax agencies on the grounds of reform strategy. Thus the ARA reform is considered a variant of the "enclave" approach to reform, which is sometimes disdained for its lack of comprehensiveness. The anti-enclave argument

${ }^{10}$ Carlos Silvani has argued that the financing mechanism should be countercyclical to protect tax administration during a recession (for example, in a recession the agency might need to hire contract workers to maintain collections). 
posits, perhaps implicitly, that it is better either to reform the government as a whole or leave things the way they are. A key assumption in this line of thinking is that partial reforms might actually make more comprehensive reforms more difficult at a later date.

Whether this argument is compelling or not depends on the potential for global reform and the goals of the reformers. If a more comprehensive reform of the civil service were possible, then this argument might hold some water. If the choice were between the ARA reform on one hand and no reform on the other, reformers might prefer the former. The anti-enclave argument also loses some of its sway given the uniqueness of the tax administration. To the extent that the whole of government relies in no small part on the tax administration, one can make a compelling case for exceptional treatment under circumstances.

Others have argued that giving special treatment to a particular organization like a tax agency would have negative externalities throughout the rest of the government, causing other civil servants to envy and disdain the reformed agency. If this were to happen, according to this line of argument, inter-agency cooperation could become problematic, perhaps resulting in less effective overall public administration.

This argument might have some truth to it, but it might also be that the potential externalities are overstated. While there is no doubt that better working conditions and higher salaries might cause envy in some civil servants, it does not necessarily follow that this envy would amount to a significant impact on performance.

A third counter-argument, which may be the most important, hinges on concerns about bureaucracy run amok. Especially given the powerful place of the tax agency in the national bureaucratic pantheon, some have been concerned that autonomization would reduce accountability and undermine the authority of the MOF. In certain circumstances this might be a legitimate concern.

The counterargument, however, is that accountability mechanisms need to be built in from the start to safeguard against administrative malfeasance. It would indeed be unwise to establish a revenue authority without any countervailing checks and balances on its autonomy. Given proper accountability features, the authority would have a much more difficult time running amok. Ultimately, however, this is an empirical question. No cases of ARAs running amok have yet been reported. 
A fifth argument against the ARA reform is that, given its comprehensiveness and potential for disruption, it could divert attention from reform of the basic functions of tax administration, including registration, collections, and audit. The validity of this argument would depend on the capacity of reformers to move ahead on simultaneous fronts. It would also depend on the design of the overall reform. Needless to say, autonomy is merely the first step: subsequent reforms would have to focus on good management, a sound tax administration strategy, and appropriate operational procedures, and the entire program would have to be sequenced according to capacity constraints.

One last argument is sometimes made against the idea of autonomy on the grounds that what really matters is professionalization, or good management, not autonomy per se. Autonomy and professionalization, however, are not mutually exclusive. To establish an autonomous authority and then staff it with unprofessional managers defeats the purpose. Appointing good, professional managers, and providing incentives for them to sustain their performance over time, are critical conditions to ensuring the success of the third party delegation solution. ${ }^{11}$

This section has set out the arguments for and against ARA reform, though ARA reform must be judged explicitly against other reform options as well. Implicit in the decision to accept or reject the ARA model is a consideration of the net benefits of other options. What is the opportunity cost of undertaking the ARA reform and foregoing other options?

The most likely other option is a gradualist approach, which often involves a strategy based on a series of modest measures. The gradualist approach is generally carried out over the long term. Chile is often cited as the example of this strategy. Chile's tax administration is among the best in the developing world, yet it is not autonomous. Chile's exceptionalism extends, however, far beyond its tax administration. Chile has had a tradition of a more professionally-oriented civil service dating from the $19^{\text {th }}$ century, and its tax administration reform program began in earnest in the 1960s. Chile's reforms have been very incremental, leading to slow but steady progress over a thirty-plus year period. Even if the Chilean model were replicable, one must ask whether other models

\footnotetext{
11 Taliercio (2000) provides a chapter on revenue authority tax commissioners (and their management strategies) in Bolivia, Mexico, Peru, and Venezuela.
} 
would produce more rapid results. The point is that the costs and benefits of a gradualist approach should also be carefully weighed in context.

In sum, the issue of autonomy should not be analyzed as if it were a question of principle. Whether autonomy is desirable or not should be based on an analysis of the expected costs and benefits of autonomy. If autonomy improves performance, then autonomy yields positive benefits. If autonomy also creates costs, then the benefits should be weighed against the costs. The decision that governments must take on the autonomy question should be based on the expected net present value of the ARA reform. The purpose of the next section is to shed light on the question of expected benefits and costs by assessing the experience of ARAs in six diverse Latin American and African countries.

\section{DOES AUTONOMY IMPROVE PERFORMANCE? EVIDENCE FROM THE}

\section{CASE STUDIES}

Overall the ARAs examined show a mixed performance record, due, in part, to the problems of sustainability associated with many of these cases (see Taliercio, 2003b). The best performers across a range of indicators have been Peru, Kenya, and South Africa, though others have had more limited success in some areas. The cases suggest two preliminary findings. First, performance improved most when autonomy was relatively high in comparative terms (Peru, Kenya, and South Africa). The corollary is that performance improved least in cases where autonomy was low (Mexico), and performance varied, initially improving then leveling off or falling, in cases in which autonomy decreased over time (Venezuela and Uganda). Second, when autonomy was stable, performance tended to improve, albeit slowly in some cases.

Thus, there is an observable trend of improved performance in the cases with some modicum of sustainable autonomy over time, suggesting that two causal factors play a role: the level of autonomy and its stability (with a likely interaction term between the two). The cases suggest that stability is necessary but not sufficient, however. Some relatively higher level of autonomy is also necessary. Put differently, greater stability can help compensate for lower autonomy. 
At the same time a word of caution is in order. The metaphor of painting a picture, rather than presenting a rigorous quantitative analysis that controls for exogenous variables, is appropriate here for a number of reasons. ${ }^{12}$ First, data availability, especially in the pre-reform period, is difficult to obtain. The ideal methodology would have been to compare performance indicators pre- and post-reform to ascertain whether there were statistically significant differences in performance. This is not possible as much data from the pre-reform period (with the exception of revenue collections) is not available.

The second challenge is that we do not currently have a rigorous methodology for evaluating tax administrations. It is difficult to measure with precision the marginal impact of tax administration reform on outcomes like revenue and debt collection, as many exogenous factors exert causal influence on these and other related outcomes. ${ }^{13}$ From economic growth to the price of oil to changes in the tax code to the effectiveness of the judiciary and police forces, tax administration-related outcomes are affected by a host of causal factors. A rigorous multivariate analysis of tax administration performance would require an enormous database which is presently unavailable (though this area is certainly a promising one for further research). Moreover, even if performance improved, the counterfactual (of no reform or other types of reform) would have to be taken into account.

The third challenge is that of measuring autonomy itself. Evaluating the amount of overall autonomy that an agency has in comparative terms is tricky precisely because autonomy is characterized by a number of different dimensions. Some agencies have more personnel autonomy than others, but less financial autonomy. Given this, to evaluate the overall level of autonomy in comparative terms one would have to assign weights to each dimension of autonomy in order to develop an aggregate measure. Assigning weights to administrative features is fraught with subjective peril; I would argue that such an approach would not add much value.

The fourth challenge is related to the problem of sustainability. In each of the cases examined autonomy has waned, and in a couple of cases waxed, over time. Thus, autonomy has been something of a moving target, which further complicates our

\footnotetext{
${ }^{12}$ On challenges assessing tax administration performance in OECD countries, see Olsson and Waltersson (N.D.).

${ }^{13}$ For a multivariate analysis of revenue performance, see Serra (2003).
} 
understanding of its impact on performance (the problem of sustainability is not addressed here; see Taliercio, 2003b).

Thus, the goal of this section is modest: to show whether or not autonomy impacted agency management, and, if it did, to tell a plausible story about how autonomy-enhanced management is linked to changes in performance. This microanalytic methodology also addresses some of the difficulties raised above by moving beyond crude macro indicators like revenue collections and clumsy indices of autonomy. The paper contends that case studies that focus both on administrative reforms as well as performance outcomes are the best way to shed light on the question of whether autonomy matters.

The section focuses explicitly on how autonomy affected agency management, including personnel management and administrative costs. A clear understanding of how autonomy shaped human and financial resource management initiatives undertaken by the ARA allows for stronger inferences about how autonomy affected organizational output and outcome indicators. The section then examines the performance of ARAs in terms of revenue collection, compliance management, and taxpayer services, qualifying to the extent possible the impact of exogenous factors and counterfactual considerations.

\section{Managing with Autonomy: Evidence from the Cases}

This section examines how managers used their autonomy to improve overall agency management, focusing on human and financial resource management. The contention is that those ARAs that made the most progress in these areas should also be the ones making the greatest improvement in organizational performance.

\section{Human Resource Management}

The major issue addressed by greater autonomy has been human resource management, given the severe problems that pre-reform agencies faced in attracting and retaining high caliber professional staff. This section argues that behind any gains in performance are internal reforms to management and personnel systems, most of which would not have been possible without autonomy. Both the KRA and SUNAT used their autonomy to make significant advances in the area of personnel management. SARS has 
used its more limited personnel autonomy creatively, while SENIAT used its autonomy to introduce important reforms at the outset, but its commitment to reform declined over time. The SAT has made little progress in this important area.

Peru is the case characterized by the most far-reaching personnel reform. Superintendent Manuel Estela and his team believed that the first priority of the new agency should be to reform its human resources. The team undertook a radical overhaul of the staff, requiring that each employee reapply for his/her job and subjecting each applicant to a rigorous selection process (see Box 1). Of the initial 3,051 workers, 2,034 were separated from the organization, leaving 1,017 (Haltiwanger and Singh, 1999: 44). During the initial reform period, SUNAT hired 1,309 workers using meritocratic criteria (exams and open competitions), bringing the total staff to 2,326 (a net employment reduction of 725 compared with the pre-reform staff complement). The costs of the retrenchment program, however, were high for SUNAT, which paid out about US\$1 million in severance payments and an additional US\$1 million in enhanced pensions, resulting in an average cost per retrenched worker of US\$1,131 (Haltiwanger and Singh, 1999: 57$)^{14}$

\section{Box 1. SUNAT's Radical Human Resource Reform}

On May $18^{\text {th }}, 1991$, President Fujimori signed an executive decree (based on powers delegated by congress) that declared SUNAT in reorganization. ${ }^{15}$ First, the decree provided all personnel with ten days to present applications for a position in SUNAT as defined by the new organic structure. Those who applied would be subject to an evaluation, and only those passing the evaluation would be rehired. Those employees who did not pass the evaluation would still receive their pensions, however. Employees also had the option to join the Program of Voluntary Retirement, in which they would receive pecuniary compensation but would not be able to work in the public sector for ten years (the decree provided a clause for the dismissal of anyone who rehired one of the disqualified workers). Lastly, the decree empowered the superintendent to investigate "indicators of immoral conduct" of bureau employees, also giving the superintendent the power to remove employees whose "exterior signs of wealth" did not correspond to their tax declarations.

Subsequent resolutions, issued by Estela, defined the "positions of confidence" in and the organizational structure of SUNAT. ${ }^{16}$ The positions to be filled by the superintendent were defined as the adjunct superintendent, the secretary general, the national and regional intendents, and the managers of the national and regional intendencies (about 50 positions in total). On June $20^{\text {th }}$, Estela's team issued a resolution which detailed the name and number of each type of position within the organization, thus

\footnotetext{
${ }^{14}$ In contrast, Peru's civil service reform (1991-1993) cost the government on average US $\$ 4,735$ per worker and only relied on voluntary retrenchment mechanisms. SUNAT's reform was not only involuntary but also much less lucrative for the separated workers. Furthermore, not one separated worker was rehired by SUNAT, whereas of the 263,654 separated in the civil service, 163,059 were rehired (Haltiwanger and Singh, 55).

${ }^{15}$ Decreto Legislativo No. 639, 5/18/91.

${ }^{16}$ Resolutions No. 269-91-EF/SUNAT (5/28/91) and No. 277-91-EF/SUNAT (6/13/91).
} 
establishing an establishment register. ${ }^{17}$ The same day Estela also issued a resolution on the voluntary retirement program, in which pecuniary rewards would be based on accumulated points as a function of occupational category and length of service. Those employees eligible to receive pensions would receive an additional bonus of $20 \%$ in exchange for surrendering the right to receive their pension.

The SUNAT reform team also believed it necessary to remove SUNAT from the public sector employment regime. In September 1991, responding to SUNAT's petition, President Fujimori issued a decree creating a new labor regime. ${ }^{18}$ The new regime permitted SUNAT to set the salaries of its employees based on their experience and the salaries of comparable jobs in the private sector. Employees also had the option, however, to remain in the public sector regime, which enabled SUNAT to argue that it was respecting workers" "rights." Moreover, the decree established a trial period of three months for all new employees (beginning after the six month training period). The decree also provided for dismissal of any employee for "lack of probity" or "abuse of authority."

Salaries, due to the new personnel scheme, increased dramatically. Whereas on average a tax administration employee earned approximately US\$50 per month in early 1991, the average salary for the remaining workers increased roughly twenty times to US\$1,000 (Haltiwanger and Singh, 1999: 44). The new salary scale ranged from US $\$ 400$ to US\$2,000 (The Peru Report, October 1991, 5). ${ }^{19}$ There is no question that SUNAT's radical personnel reforms - characterized by retrenchment of two-thirds of the staff and huge increases in salaries - would not have been possible without autonomy, and that the personnel reforms were among the most important for the success of the overall reform.

In Venezuela, on the other hand, it was decided that there would be no involuntary separations. As a result of the voluntary departure and retirement programs, which allowed retirees to collect more than three times the amount that normally would have corresponded to them, about 850 employees left the tax agency (the plan made retirement conditions more flexible, thus expanding eligibility). An additional 350 employees, who were transferred automatically to SENIAT but did not meet the minimum requirements for employment according to new personnel regulations, retired. The voluntary downsizing represented $25.5 \%$ of the total staff.

Though the political establishment would not permit Superintendent José Moreno León to undertake radical human resource reform, it did permit him to appoint the entire managerial level of the organization. Thus Moreno León was able to hire nearly 500 new professionals from top private sector accounting and law firms, which resulted in a vast improvement of the managerial ability of the organization. Moreno's plan was to

${ }^{17}$ Resolution No. 280-91-EF/SUNAT (6/20/91).

${ }^{18}$ Decreto Legislativo No. 673, 9/23/91.

${ }^{19}$ The personnel reform cost SUNAT US\$47 million in present value terms (Haltiwanger and Singh, 1999: 44 ), roughly US\$20,200 per worker on average. 
introduce the professional civil service gradually, while eliminating the worst cases of corruption with his new personnel statute.

In Mexico the SAT's Fiscal Career Service (SFC), intended to be a merit-based system, did not quite get off the ground during the initial reform period. Due to union opposition, entry into the SFC was made optional for existing employees and mandatory only for new employees. In addition, the SFC was to cover only a certain percentage (unspecified) of employees; that is, there would still be a category of "freely designated" employees, who would not have to fulfill any SFC requirements. This category not only included high level managers, but also specialists and technical professionals.

Survey data on the reforms in Latin America are consistent with the above evaluation of the extent of personnel reform. Indeed, the differences are highly pronounced. Perceptions of SUNAT's and SENIAT's human resources are much more favorable than those of the SAT's. Eighty five percent of Peruvian respondents said that tax agency employees are Frequently, Mostly, or Almost Always more qualified professionally than other public sector employees, as compared with $75 \%$ in Venezuela, and $52 \%$ in Mexico. In terms of the impact of the reform, $81 \%$ in Peru and $61 \%$ in Venezuela said tax agency employees were Substantially or Much More Qualified now than before the reform, as opposed to $16 \%$ in Mexico. ${ }^{20}$

The African cases also show a mixed record in personnel management, from Kenya, where the reforms were consistently moving in the right direction, to Uganda, which showed forward as well as backward movement. The advent of the KRA is widely regarded to have increased the professionalism of the tax agency's staff and reduced, though not eliminated, the level of corruption. KRA improved staff quality through a number of measures. The KRA increased salaries in real terms, which was a break from the previous salary policy, and actually reduced the total number of staff by over $30 \%$ over a five year period, with the major change coming from the retrenchment program of 2000. These reforms would not have been possible without autonomy.

The KRA instituted a merit-based promotion system and established a personnel regime in which staff can actually be dismissed fairly easily by KRA management. Managers are empowered with "day to day autonomy" that allows them to fend off

${ }^{20}$ Taliercio (2000, 336). 
pressures to engage in patronage. KRA's code of conduct and the board disciplinary committee have also played important roles in improving the professionalism of the staff. KRA's training programs are more relevant now because they are tailor-made by KRA officials themselves, instead of the public service commission.

The KRA has also made gains in administrative efficiency. Since the founding of the KRA, the size of the staff complement has declined year after year. The complement inherited by the KRA of approximately 4,500 in June 1995 shrunk to 4,002 in June 2000. The net decrease of nearly 500 employees occurred through a combination of attrition and disciplinary measures, even though new staff were also recruited during this period. A further 830 staff were retrenched in December 2000, leaving approximately 3,140 in $2001 .^{21}$ Though the majority were retrenched for poor performance, about $40 \%$ left voluntarily.

Using the salary scales of the central bank and Kenya Commercial Bank as references, management established a new KRA salary scale. ${ }^{22}$ Funding constraints, however, prevented wholesale adoption of the new scale. Moreover, there was a sense that applying the new competitive salary scale across the board and in the absence of a retrenchment exercise would have been inefficient. Consequently, the scale was applied only to top management. The remaining $98 \%$ of staff were given several annual across the board raises over the KRA period, but their salary position has not improved nearly as much as that of top management. ${ }^{23}$ Indeed, in 1996 KRA increased its total wage bill by $49.1 \%$ in real terms.

In the case of South Africa, SARS was granted some autonomy over personnel management and has used its autonomy, subject to approval by the MOF, over the past several years to modernize its personnel system. Though SARS inherited the civil service system in 1997, it introduced its own personnel system in January 1999. As a result of the

\footnotetext{
${ }^{21}$ According to KRA management, the retrenchment plan was discussed since KRA's inception. Opposition from the government and inadequate funding from the treasury resulted in the plan being postponed for several years. Of these retrenched, over 550 were support staff. The program was estimated to cost approximately Ksh. 360 million. It is worth noting that KRA's retrenchment package was more attractive than the one offered by the government.

${ }^{22}$ The KRA scale subsequently became a model for the greater public sector and was used by KACA, which is also characterized by greater autonomy.

${ }^{23}$ The data do indicate, however, that the KRA was serious about increasing wages within its budget constraint. The average annual real wage bill increase for the period 1996-2000 was $12.8 \%$, as compared with $-16.7 \%$ in the pre-KRA period (1991-1995). The difference is statistically significant at the $95 \%$ level.
} 
collective bargaining process, all previous inland revenue and customs and excise staff were automatically transferred to SARS. The fifty staff levels of the old system were reduced to thirteen and a system of competitive, market-referenced salaries was established. SARS staff do earn more than their civil service counterparts, though after the recent civil service wage increase the difference is not that great. The limitations on SARS autonomy, reinforced by political concerns, appear to have limited the extent to which SARS can pay more than the public sector at large.

The central problem with SARS current compensation system is retention of its highly skilled employees, particularly auditors and tax lawyers, who have experienced a high rate of turnover due to "poaching" by the private sector. ${ }^{24}$ The problem of poaching is particularly acute in SARS LTO, which has experienced almost $100 \%$ turnover in its audit staff in approximately three years. This has occurred in spite of SARS's overall turnover rate of $6 \%$, which is quite low compared to the national (public and private sector) average of $13 \%$. Some managers are concerned, however, that SARS audit department is treated as a training ground by the private sector.

SARS has used its autonomy to respond pro-actively: it implemented an experimental provision by which supplementary premiums (10\% in 2001) can be paid to employees with scarce skills. Furthermore, it is using experimental performance contracts by which an additional $20 \%$ can be made available (this was piloted with the auditors in the SARS LTO). Thus, experienced auditors in the LTO could receive a premium of up to $30 \%$ of their standard salary. SARS autonomy permits it to respond selectively and flexibly to the problem of auditor poaching.

The SARS personnel system developed an interim performance evaluation component which was initially operational only for senior managers, and was scheduled to be rolled out to all staff after the pilot phase. Previously, however, SARS had implemented a radical performance reward system. Given that SARS had not undergone an initial retrenchment, and that its new personnel system was not introduced for two years after its founding, SARS management deemed it necessary to take a bold step regarding performance rewards in order to jump start the reform. Over a three year period from 1996-1999 an average of 46\% of annual salaries was paid out to staff as

\footnotetext{
${ }^{24}$ Interviews, SARS general managers, , Pretoria, South Africa.
} 
performance bonuses. The total bonus available was calculated as a function of the amount by which SARS exceeded its annual revenue targets. The bonus system, which was extremely popular with staff, served as a substitute for salary reform. Once the new compensation system was introduced, the bonus system was scaled back considerably.

SARS management has an ambiguous take on the popular yet controversial bonus system put in place in the early stages of the reform. On the one hand many SARS managers believe that the bonus system was largely responsible for SARS improved revenue collection performance. On the other many believe that the lack of discrimination inherent in the bonus system was inefficient, rewarding slackers as well as high performers. Moreover, given the system's near exclusive focus on collections, other important issues like taxpayer services were somewhat neglected as a result. One view from the private sector is that the incentives fomented a "prosecutorial mentality" among staff, a perception that would tend to undermine SARS's credibility by calling its commitment to fair, impartial treatment of taxpayers into question. ${ }^{25}$

The size of SARS's staff has decreased from 11,942 in 1999 to 10,847 in 2001 , nearly a $10 \%$ decrease over the period, demonstrating further efficiency gains as a result of autonomy coupled with good management. ${ }^{26}$ SARS has also moved forcefully against cases of corruption and has dismissed 173 employees for misconduct since 1998, representing about $1.5 \%$ of the total average staff over the period. There is a perception, both in SARS and the business community, that corruption in the tax agency has decreased since SARS founding and that taxpayer services have improved over the same period. This is due, in part, to the perception that the overall quality of staff has improved over the period.

SARS personnel flexibility enables it to adopt different employment modalities depending on its needs. For example, SARS outsourced its IT staff from 82 different private companies. Each contractor was hired on a one year renewable contract, and, after two years all positions were retendered. The tendering process took place outside of the collective bargaining arrangements (the contractors are not unionized). This arrangement

\footnotetext{
${ }^{25}$ Interview, South African Chamber of Business, , 7/23/2001.

${ }^{26}$ This decrease is somewhat offset by the fact that the number of contract employees has increased slightly from 337 in 1999 to 509 in 2001, and that SARS hires 272 IT consultants on short term contracts for its technical services department.
} 
allowed SARS to solve the serious problem faced by its predecessor of attracting and retaining qualified personnel in the IT department.

SARS management regarded its experimentation with personnel reform thus far to be quite successful. Moreover, it believed the organization has served as a role model for both the public and private sectors. SARS believed, for example, that new dispensations for managers in the civil service, as well as other terms and conditions of service, reflected SARS practices. In addition, SARS has informally advised other parts of government on its wage negotiations. The reform of SARS seems to have had something of a positive impact on the wider government.

Of the African cases the URA has shown the least progress in human resource management. When the URA was established in 1991 it launched a program of interviews in order to vet the staff of the previous tax departments. As a result of this process roughly three-quarters of the URA staff was hired from the MOF; the rest came from other parts of government, including a small number from the private sector. All management staff were hired on three year renewable contracts, while non-management staff were appointed on probation for two years. During 1993 and 1994 staff on probation were evaluated and a number (about $7.5 \%$ of total staff) were terminated for unsatisfactory performance.

The size of the URA's staff has grown by nearly $90 \%$ since 1992, increasing from 1,208 to 2,269 in 2001 (though the URA has an approved establishment of 2,553). ${ }^{27}$ This increase occurred in spite of the 1995 corporate plan. ${ }^{28}$ The expansion of URA's staff has been due in part to the expansion of its operations. In addition, however, the expansion is due to the low level of capital investment over the past decade. At the same time, inadequate management also seems to bear some of the blame. For example, the merger of the inland revenue and VAT departments did not result in the reduction of staff, even though certain functions were being duplicated. Political interference is also a source of problems, according to senior managers (there have been cases in which individuals dismissed by management have continued reporting to work). Part of the problem seems to be that when salaries are increased in the absence of an airtight merit-based personnel

\footnotetext{
${ }^{27}$ Approximately $51 \%$ of the staff establishment is administrative (level 11 and below).

28 "URA Corporate Plan, Third Edition," 1995/96, p. 22.
} 
system (that is, when government interference is still common), patronage pressures may increase.

Turnover has been considerable, however, when one takes into account the fact that a total of 647 employees were dismissed or terminated their employment with the agency between 1993 and 2001 (of these 257 were dismissed, mostly on account of corruption). The highest turnover rates have occurred in the IT, accounting, and auditing areas, in which URA is paying considerably less than market rates.

In 1991 the fledgling URA increased salaries in order to attract private sector professionals and to motivate their ex-civil servants to improve job performance. Compared with the existing civil service salary structure, remuneration increased severalfold. The initial increase in salaries, however, has not kept place with inflation. Between 1991 and 2001 only one further salary increase took place. In 1998 the URA sought approval from the MOF for a revision of its salary scales. The MOF approved, but declined to provide any additional funding. As a result remuneration (salaries plus benefits) for high-level technicians has declined by approximately one-third since the mid 1990s. ${ }^{29}$

Autonomy has also mattered in another important way in the case of URA: expatriates can be hired easily as staff, unlike in the public service. This is not a trivial point, as expatriates have come to play an important role in the development of the URA (the current $\mathrm{CG}$ is a European expatriate), serving as a substitute for an institutional bulwark against patronage pressures.

The Peruvian, Kenyan, and South African cases show the greatest commitment to human resource reform. The case of SUNAT is clearly the most far-reaching. SUNAT instituted a radical retrenchment program, increased salaries dramatically, and established a well-regarded in-house training institute. In Kenya there was a quasi-voluntary retrenchment, carried out in the context of declining staff numbers, and a selective increase in salaries. The KRA also provides training programs (out-sourced) for its staff. Survey and anecdotal information indicates that corruption decreased in both SUNAT and KRA as a result of the reforms. SARS did not undertake a retrenchment program,

\footnotetext{
29 "Medium Term Revenue Framework: Comparative Analysis of URA Salaries in 1994/95 and 2000/01," URA.
} 
though it has reduced staff numbers slightly. Salaries were increased, though not dramatically. The controversial performance bonus tied to collections has been phased out, and it remains to be seen whether the salary scale will suffice to attract and keep talented labor. SARS has also been flexible in using special initiatives to deal with specific personnel problems, and provides excellent training opportunities for its staff.

The Venezuelan, Mexican, and Ugandan cases show less progress in this important area. SENIAT introduced a voluntary retrenchment program, which reduced staff numbers initially, and hired top private sector accountants and lawyers to manage the reform. The SAT's experience with personnel reform was lackluster, and Mexico continued to have the lowest ratio of taxpayers to tax officials of the countries considered. The URA did not initially downsize the organization, and, in fact, increased the staff complement over time, though it did sporadically increase salaries. Increasing salaries without undertaking some kind of retrenchment program might actually have adverse effects.

\section{Financial Resource Management}

The cases show that these gains in performance have not come at great financial cost. As Table 1 shows, all ARAs, with the exception of Uganda, had reasonably low collection costs (taking $2 \%$ as the benchmark). Moreover, the more autonomous ARAs tend to have lower average collection costs (recurrent costs expressed as a share of collections) than the less autonomous ones. Kenya, Peru, and South Africa are all at the low end of the set. At the same time ARA collection costs (as an average of these cases) are comparable to or less than those of non-autonomous developing country tax agencies.

Table 1: Average Collection Cost as a Percentage of Revenues Collected

\begin{tabular}{ll}
\hline COUNTRY & AVERAGE COLLECTION COST \\
\hline Peru & $1.9 \%(1996-1998)$ \\
Mexico & $1.7 \%(1995,1997-1998)$ \\
Venezuela & $2.0 \%(1995-1998)$ \\
Kenya & $1.2 \%(1995-2000)$ \\
South Africa & $1.1 \%(1998-2001)$ \\
Uganda & $3.6 \%(1991-2001)$ \\
Average & $1.9 \%$ \\
\hline Source: Author's calculations from ARA and MOF data, and Taliercio (2000).
\end{tabular}


SARS collection costs have consistently been the lowest of the cases examined, ranging from $0.90 \%$ to $1.16 \%$ of revenues collected (the average over the period 1998 2001 was $1.00 \%) .{ }^{30}$ SARS's low cost level put it on par with a number of OECD countries in terms of cost to collections efficiency, though the cost ratio has risen consistently since 1998, reflecting increased allocations.

In spite of the reforms, and the increasing budgets that went along with them in some cases, one could argue that most of the ARAs remain underfunded. The URA, for example, lacked equipment and infrastructure, including an IT system, due to an underfunded capital budget (in some years the URA's capital budget was nearly zero). The lack of a proper IT system alone seriously undermined the URA's performance, from registration to assessment to compliance.

The KRA also reported inadequate resources for IT investment and for rolling out the higher KRA salary structure to the entire staff. The KRA operated on a tight budget in comparative perspective. The government, however, provided a modern office building to KRA (Times Tower), which ought to have had the effect of improving the agency's professional image. Given its very low collection costs, the record of the KRA appeared even more impressive in comparison.

Though SARS has had an increase in investments since 1997, and some of these were quite significant, especially in the IT area, its capital budget was somewhat low. The percentage of SARS capital expenditures to its total budget, which was in line with the other cases, stood low at approximately seven percent (personnel expenditures account for roughly half of the SARS budget). ${ }^{31}$ The LTO, for example, reported a lack of basic infrastructure and key items such as laptop computers.

Thus the cases show that these reforms have not generated high recurrent cost obligations in comparative terms. In the best cases increases in salaries were offset by staff reductions. The case studies do suggest, however, that capital expenditure is limited to the point of creating inefficiencies for several of the agencies. The cases also show that the start up costs of the reform-including for retrenchment and purchase of new

\footnotetext{
${ }^{30}$ Calculations based on SARS data. Using 2001 budget data (Estimates of National Expenditure), the average collection costs ratio rises to $1.10 \%$ over the same period and does not show a steady increase.

${ }^{31}$ These figures do not include special capital investment projects, financed separately by the MOF, in the IT area.
} 
buildings - can indeed be high, suggesting the need for special one-off funding of initial investment costs.

\section{Organizational Culture, Flexibility, and Corruption}

An important intangible consequence of reform is the impact of autonomy on organizational culture. Managers and observers report that in several cases, notably Peru and Kenya, autonomy had a significant impact on organizational culture. In the case of Kenya, autonomy is reported to have created a corporate identity where one had not previously existed. In Peru SUNAT is said to have generated a mistica, or organizational mystique, that motivated staff to maintain professional standards and improved their incentives for good performance.

Innovative management practices have had far-reaching impacts in a number of the cases examined. In Kenya, for instance, the KRA improved its procurement process by developing its own regulations, which led to a decrease in the number of "fake tenders" and served as a model for the central government, which used the KRA regulations to reform its own procurement practices.

In Kenya the KRA's board promoted good relations with the private sector by encouraging the KRA to take a fair-minded approach toward dealing with taxpayers and their representatives. KRA management made it a point of meeting with professional organizations to discuss issues and problems of common concern. Many saw the board as having "narrowed by gap between the tax administration and the taxpaying public" by promoting greater openness and transparency. At the same time private sector representatives on the board provided KRA management with useful information on which problems taxpayers saw as most vexing. ${ }^{32}$

In the South African case the benefits of additional autonomy to managers were clearly apparent. Pre-SARS the tax administration was procedure- and control-driven. Managers reported being able to implement organizational change much more quickly and effectively than before reform. The case of the large taxpayers office (LTO) is illustrative. Before SARS was established, the commissioner of inland revenue

\footnotetext{
${ }^{32}$ Not all observers, however, share the same view. There is a view, although it seems to be a minority one, that board appointees are political and thus of limited use for expressing the private sector's concerns.
} 
attempted, unsuccessfully, to set up an LTO. The former commissioner reports going through a series of frustrating experiences, from first seeking special funding from the MOF, to purchasing an appropriate building, which took about one year, to getting permission to hire high caliber accountants for the unit, and then contracting them, which took about two years, to having the funding revoked because too much time had passed, to seeing the endeavor fail because high caliber accountants could not be contracted with low public service salaries. ${ }^{33}$ Though there is room for improvement in the SARS LTO, establishing and supporting the unit has been much easier given the agency's autonomy.

SARS management also used its autonomy to support organizational accountability by establishing an internal audit division in 2000. SARS also reduced corruption in its tendering process by managing it more closely, according to the AG. Still, SARS managers acknowledged the need for further reform in the procurement regulations to reduce the timeframe for contracting and increase flexibility (SARS's tender board functions according to public sector statutes).

SARS' autonomy also allowed the agency to be more proactive and flexible. For example, SARS created regional offices to decentralize power to managers closer to taxpayers. SARS also had the flexibility to undertake special projects as necessary, including prosecution and revenue initiatives with special incentives for staff.

SARS consciously cultivated a corporate image of probity, fairness, and effectiveness, in part by crafting a public relations strategy through an active public relations department. SARS has attempted to change its organizational culture to one focused on performance and integrity, and has succeeded in doing so. SARS also cultivated its image by going after criminal convictions for tax evaders as "quick wins." According to the commissioner, SARS needed a "bite in its bark." 34 There is no doubt that SARS' autonomy allowed managers to innovate more quickly than would have been the case without autonomy. According to a representative of the SAICA, "Our concern is that the tax administration is running ahead of us and it's now going to be us chasing to catch up with Revenue, and that's putting stress on our members." 35

\footnotetext{
${ }^{33}$ Interview, Trevor van Heerden, Pretoria, 7/24/2001.

${ }^{34}$ Interview, Pravin Gordhan, Pretoria, 7/24/2001.

${ }^{35}$ Interview, SAICA representative, Pretoria, 7/23/2001.
} 
Survey data also reveal that taxpayers' perceptions of corruption vary, as a result of the reforms. ${ }^{36}$ Indeed, the differences are striking. In Peru $73 \%$ of respondents classified the agency's corruption level as Fairly or Very Low, as opposed to 20\% for Mexico and $6 \%$ for Venezuela. In contrast, $29 \%$ in Venezuela classify corruption as Fairly or Very High, as compared with 17\% for Mexico and 2\% for Peru.

In terms of the impact of the reform on corruption, Peru again surpassed the others, with $85 \%$ responding that there was Substantially or Much Less corruption than before the reform, as compared with only 26\% in Venezuela and 21\% in Mexico. The relatively smaller impact in Venezuela reflects the perception of backsliding since the reform, whereas the value for Mexico reflected the perception of the of reforms' minor impacts.

Of the African cases, Kenya and South Africa have gone farther than Uganda. Uganda, however, was not without some progress in this area. It is thought that the URA reform has reduced the amount of corruption in the tax agency, as compared with the prereform agency, and has reduced the impunity of the corrupt officials that remain. The combined effect of higher salaries and stiffer penalties for malfeasance vis-à-vis public service employment conditions seems to have made an impact. The URA reform is reported to have led to less moonlighting. The URA recently established an on-line recruitment system, in which specific posts are advertised against the establishment register and application processing is handled electronically.

Very encouraging is the perception in Kenya, held by both KRA officials and private sector tax experts, that corruption has decreased since the reform. According to one professional tax accountant, "I'm less likely to get asked for a bribe than in the old days. ${ }^{~}{ }^{37}$ However, as would be expected, significant corruption still exists, especially in customs. According to a previous Commissioner General (CG), "elaborate schemes of fraud exist. ${ }^{38}$ Yet in order to reduce corruption further, additional resources and perhaps additional autonomy, will be required.

\footnotetext{
${ }^{36}$ Survey data from Taliercio (2000).

${ }^{37}$ Interview, Nairobi, Kenya, 7/6/2001.

${ }^{38}$ Interview, Nairobi, Kenya, 7/4/2001.
} 


\section{Performance in Practice: Evidence from the Cases ${ }^{39}$}

This section analyzes the performance of the ARAs in three broad categories of indicators: revenue collection, compliance management, and taxpayer services. The focus on compliance and taxpayer services is important to round out the picture provided by looking at collection indicators, since collections are only partially determined by tax agencies.

\section{Revenue Collection and Efficiency}

Most ARAs have been successful in the most basic of their tasks: raising revenues. ${ }^{40}$ SUNAT increased total tax revenues ${ }^{41}$ from $8.4 \%$ of GDP in 1991 to $12.3 \%$ in 1998, during which time tax policy reforms included the rationalization of the tax structure and the reduction of many tax rates (more recent data show collections falling to about $11 \%$ and then recovering to nearly $12 \%$ in 2003$).{ }^{42}$ SENIAT increased total revenues from $5.9 \%$ of GDP in 1994 to $8.5 \%$ in 1998, though the increase was due in part to the introduction of a new sales tax. SUNAT and SENIAT also increased their revenues in real terms over the 1990s. Mexico's SAT, which benefited from the least autonomy, increased revenues only marginally from 1996-1997 (see Figure 2).

\footnotetext{
${ }^{39}$ For more data and analysis, see the appendix.

${ }^{40}$ All data sources are national tax agencies, unless otherwise noted. Latin American data from Taliercio (2000).

${ }^{41}$ All data for the Latin American cases exclude customs revenues, unless otherwise noted. All data for the African cases include customs revenues, unless otherwise noted.

${ }^{42}$ For a more recent analysis, see Mann (2004).
} 
Figure 2. Tax Revenues as a Percentage of GDP, 1990-2000

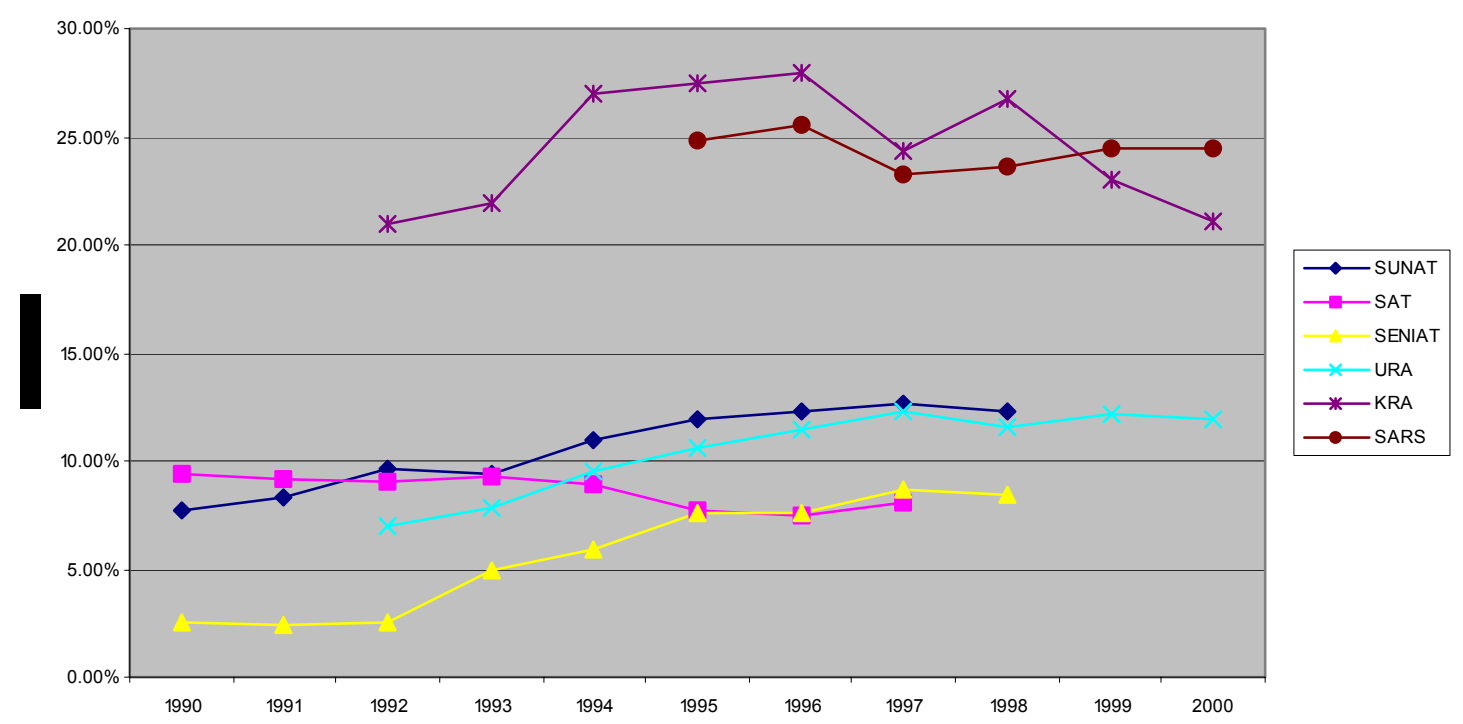

The URA had one of the most spectacular increases in revenues as a percentage of GDP: from $7.0 \%$ in 1991 to $11.9 \%$ in 1999 . Over the course of the 1990 s, however, tax policy changes, including the introduction of the VAT (and the subsequent increase in VAT coverage) and the reduction in the number of exemptions, also played a role in boosting revenues.

In Kenya total revenues declined from $27 \%$ of GDP in 1994 to $21 \%$ in 2000 , though the decrease was due largely to major tax policy reforms, including the significant reduction of tax rates across the board (the reduction of the top marginal income tax rate from $40 \%$ to $30 \%$, the top import tariff rate from $45 \%$ to $25 \%$, and the standard VAT rate from $18 \%$ in 1995 to $15 \%$ in 2000). The accomplishment of the KRA was to maintain revenues by increasing administrative efficiency in the context of drastically reduced tax rates. Consequently, the KRA exceeded its revenue targets in three years over the five year period (1996-2000) after its establishment. Indeed, though the VAT rate standard rate was $15 \%$ in both years, the ratio of total VAT collections to GDP increased from $5.0 \%$ to $5.4 \%$ from 1997 to 2000 .

In South Africa the share of tax revenues to GDP decreased slightly from $24.8 \%$ to $24.2 \%$ over the period $1995-2001$, owing largely to changes in tax policies, the net 
effect of which was to reduce revenue collections to GDP consistent with the MTEF. ${ }^{43}$ SARS, like the KRA, was successful in supporting collections in the face of declining tax rates and other revenue-negative policy changes. What the data show is that the introduction of ARAs is associated in most cases with either significant increases in revenue collections or maintenance of collections in the face of significant tax policy change.

In order to increase the ratio of revenue collections to GDP, ARAs had to post impressive grow rates in collections. SUNAT's collections grew by an average of nearly $11.5 \%$ in real terms in the first years after the reform (1992-1995), while SENIAT's total revenues increased by 5\% (1996-1997) in real terms annually. The URA's annual average growth rate ran to more than $24 \%$ in nominal terms (1995-1997). At the same time, in the cases of Peru and Uganda, growth rates tended to fall as the impact of the initial policy reforms wore off and collections became more determined by administrative practice than tax policy. In the Kenyan case revenues declined in real terms by only $6.7 \%$ from 1995 to 2000 in spite of decreases in tax rates for all major taxes, reflecting, in part, the improved administrative efficiency of the KRA. In South Africa the SARS also helped increase revenues by over 99\% from 1995 to 2001 in nominal terms, and over $32 \%$ in real terms. The average real annual growth in revenues over the period was $5.7 \%$.

An analysis of VAT productivity (that is, the ratio of GDP generated by the VAT to the VAT rate) shows that Peru is the most productive (0.32), followed by Mexico (0.26), Uganda (.25), and Kenya (.19). ${ }^{44}$ Though the KRA ranks lower in comparison to other revenue authorities, it showed a very slight improvement in VAT productivity over the period (pre-KRA average VAT productivity was 0.18 while the post-KRA average increased slightly to 0.19). Perhaps more importantly, VAT productivity post-KRA shows less deviation than before the reform, when year on year productivity was erratic. Even this indicator, however, does not unambiguously rate administrative performance. ${ }^{45}$ Interpretation of the Mexican case is also complicated by the fact that the Mexican VAT has the most highly eroded tax base of the Latin American cases examined.

${ }^{43}$ For example, tax policy changes proposed in the 2001 budget were estimated to have a fiscal cost of approximately $4 \%$ of projected revenues.

${ }^{44}$ Calculations exclude VAT collected on imports for comparability (as some ARAs incorporate customs and some do not) and to focus on internal tax administration.

${ }^{45}$ Using GDP is also less accurate than using consumption data (taxable consumption is the best measure). 


\section{Table 2. VAT Productivity a/}

\begin{tabular}{ll}
\hline Country & Productivity Rate \\
\hline Peru (1994-1998) & 0.32 \\
México (1990-1997) & 0.26 \\
Uganda (2000) & 0.25 \\
KRA (1996-2000) & 0.19 \\
\hline \multicolumn{2}{c}{ Source: Author's calculations. } \\
a/ Calculated net of VAT collections on imports.
\end{tabular}

The cases show impressive increases in tax effort in Peru and Uganda, coinciding with the introduction of the revenue authorities there, and some progress in Venezuela and South Africa, which also coincides with the ARA reforms. They also show that tax effort declined in Kenya, though the data would suggest that this occurred primarily as a result of tax policy changes. In Mexico collections stagnated and then declined; the data suggest that tax administration rather than tax policy were to blame. Though revenue collections is a very crude indicator of administrative performance, owing to the large number of exogenous factors influencing collections, the cases show that the ARA reforms are associated with significant improvements in revenues in some cases.

\section{Taxpayer Registration and Compliance Management}

The foundation of compliance is the ability of the tax agency to keep a current registry of taxpayers to ensure that they are submitting their tax declarations and making their tax payments according to schedule. Equally important is the ability of the agency to broaden the tax base to cover all the taxpayers who legally ought to be paying taxes. The cases show that Peru and South Africa have done well here, and that Kenya has made some strides in the area of taxpayer registration. The other cases demonstrate less progress.

Peru was one of the most successful in broadening the tax net, as the number of active registered taxpayers increased from 895,000 in 1993 to 1,766,000 in 1999. At the same time, the quality of information taxpayer registries is often a major problem. Peru, however, continually cleaned its registry, and, from 1995 to 1998 purged the registry of about $15 \%$ of inactive taxpayers per year. SUNAT has been able to increase in absolute terms the number of taxpayers filing declarations every year since the creation of the 
taxpayer registry in 1993, which is indeed impressive. At the same time only $35 \%$ of taxpayers have filed on average over the period, and SUNAT has not been able to increase the relative amount filing (as a percentage of those registered).

A more detailed analysis shows that SUNAT has been using its limited resources judiciously. Data from 1997 show that SUNAT has focused its efforts on large and medium taxpayers, and has been extremely successful in the process. The 33,300 large and medium taxpayers are well-controlled by SUNAT: the ratios of those declaring and paying are $100 \%$. The same ratios for the general and other simplified regimes, however, were quite low.

The data available for Venezuela allow for a limited comparison, revealing that SENIAT's control over its large taxpayers was weaker when compared with SUNAT's. The absolute number of non-filers in SENIAT's large taxpayers unit increased steadily since 1995 , nearly tripling by 1998 . The average percentage of non-filers to the number of large taxpayers registered was $32 \%$ over the period, suggesting a large hole in the administration's effort to increase compliance.

Another useful indicator of administrative performance is late payments by taxpayers (total late payments by taxpayers during the year). Data also showed that the number of large taxpayers in Venezuela making late payments increased since 1995, more than tripling by 1998 , though the amount of taxes paid late as a percentage of total collections was quite small (about 1\%).

In South Africa SARS steadily broadened the tax net with impressive year on year growth. From March 1996 to March 2001 the number of taxpayers with active status grew from 518,649 to 976,720 for corporate income taxpayers; $1,929,274$ to $3,187,072$ for individual income taxpayers; 388,454 to 450,630 for VAT taxpayers; and 188,841 to 211,425 for PAYE taxpayers. From 2000-2001 the percentage of active individual taxpayers grew by $13.9 \%$ while the growth of active corporate taxpayers reached $16.3 \%$. Note that the growth of corporate taxpayers was due principally to compliance activities by SARS as company registrations did not grow much over the same period. ${ }^{46}$

\footnotetext{
${ }^{46}$ Some component of the slow growth in the VAT registry is due to change in the threshold for registration.
} 
An analysis of the returns outstanding as a percentage of the population of active registered taxpayers showed that SARS has made progress in some areas, notably income tax, but not in others, notably pay as you earn (PAYE). SARS also continued its efforts to increase filing compliance though an on-going clean up of the taxpayer registry. One of the difficulties faced by SARS was that there was no single taxpayer identification number (TIN). SARS initiated changes to improve taxpayer registration, including the establishment of an electronic link with the Registrar of Companies in 2000, such that firms registering with the Registrar were automatically registered with SARS.

SARS, like many other tax administrations, was less successful reducing the amount of taxpayers' arrears. In fact, arrears grew over the SARS period, from 4.01 billion Rand in March 1996 to 13.24 billion in March 2001 for income tax, 2.70 billion to 11.86 for VAT, and 0.14 to 4.38 billion for PAYE. Moreover, more than two thirds $(68 \%)$ of the arrears were over nine months of age.

SARS also made some progress with the establishment of a large taxpayers office (Corporate Tax Center, CTC), though the results were not wholly satisfactory. Overall implementation of the CTC reform was disappointing, in part because of SARS' inability to attract and retain high quality staff.

The registration picture was clouded in Kenya due to a botched PIN implementation, and poor follow through thereafter, in the pre-KRA period. Overregistration led to a low proportion of active taxpayers as a percentage of the total number registered. The problem was that it was difficult for the KRA to ascertain whether firms that did not file or pay taxes were legally or illegally inactive.

The KRA, however, was quite successful in increasing the number of VAT taxpayers in its registry, which grew from 17,106 to 26,591, an increase of more than $55 \%$ from 1997 to 2000 . Yet, the KRA faced problems enforcing filing compliance among VAT taxpayers. The percentage of non-filers stood at $29 \%$ at the end of 2000 . The major problem confronting the KRA in the area of registration and filing was the lack of integration of its databases, which required that staff carry out important work manually. Management also failed to integrate the registration function, as separate identification numbers were required for different taxes (VAT and income) and separate offices were charged with the registration function (management argued that a new IT system was 
necessary to integrate the VAT and income tax databases, though that budgetary limitations prohibit the necessary investments).

KRA's Large Taxpayer Office (LTO), established in 1998, was able to streamline and improve service quality. The establishment of the LTO was facilitated by the agency's autonomy, which allowed the CG to make and implement the decision. The KRA pursued a policy of posting its best staff to the LTO, which, as a result, improved monitoring of taxpayer compliance. For example, on-time quarterly payment compliance improved from about 85\% in 1998 to about 99\% in 1999.

Two additional objectives on which KRA focused are issuing refunds in a timely manner and collecting tax arrears. KRA's management of VAT refund claims improved considerably since 1997, most notably in the reduction of the refund backlog from approximately 6.2 billion Kshs in 1997 to about 400 million Kshs in 2001. Moreover, refund claim values represent a backlog of less than one month in 2001, which was relatively low in comparison to other developing countries. The KRA was less successful at arrears collection. As of 2001 the KRA was owed approximately Kshs 52.8 million, representing about $70 \%$ of income and domestic VAT collections in that year. The ability of the tax agency to collect arrears, however, was also subject to exogenous factors, including the judiciary, which has had a major impact on the KRA's ability to enforce collections.

In the case of the URA taxpayer registration performance was disappointing overall. For example, the number of registered taxpayers in the LTO was only 317 in 2001. Moreover, of these only $86 \%$ and $85 \%$ paid the corporate income and VAT, respectively. At the same time it was reported that LTO's tax assessments have a high error rate. The Internal Revenue Department reported nearly 184,000 registered taxpayers in 2001, of which only 39,000 were active, and, of these, only 4,712 and 5,236 (13.4\%) filed corporate income tax and VAT returns, respectively. ${ }^{47}$ Of those filing VAT returns, only 50.4\% filed returns with payments in May 2001. The low active to registered ratio, as well as the high shares of non-filing and non-paying taxpayers, was partly a reflection of the inadequacy of the taxpayer registry and partly a reflection of low compliance rates.

\footnotetext{
${ }^{47}$ There are questions about the reliability of URA data on taxpayer registration.
} 
The URA was clearly not able to validate its taxpayer registry. Nor was it able to strengthen its TIN system by purging it of inactive entries. Though not all of the blame should be attributed to the URA (problems, including alleged corruption, in the Registry of Companies have undermined URA's taxpayer registry), the failure to expand the tax base (many small firms and informal traders have escaped the presumptive tax, which has proved costly to administer) and document taxpayer registration were two of the principal failures of the URA reform.

In terms of compliance management SUNAT, the KRA, and SARS made significant progress, while other ARAs have made only minor headway at best. It should be noted, however, that of all the performance indicators evaluated, the number and quality of audits seem to have fared the worst across the board.

Peru's audit presence for its largest taxpayers was estimated at nearly $11 \%$ in 1999. SUNAT's audit presence at the national level, however, was only $1.45 \%$, yet in comparative terms this was an impressive rate (given that this figure includes only actual field audits and not other kinds of minor audit acts). These data are even more impressive when compared with the pre-reform audit presence. The audit presence in 1991 was $0.17 \%$, indicating an increase of more than $8,000 \%$.

An analysis of SUNAT's audits and audit findings in February 1999 revealed that some form of non-compliance (defined as non-compliance with any formal requirement) was quite common (the overall non-compliance rate was 75.4\%). The non-compliance rate was even higher for the largest taxpayers: $90 \%$. While SUNAT's audits were able to uncover non-compliance they were clearly not able to thwart it.

Mexico, with over six million taxpayers, relied more on mass operations and certified public accountant (CPA) audits than it the traditional tax agency audit. On average (1996-1998) less than $10 \%$ of all the SAT's audit acts were actual comprehensive or specific item field audits. Nearly $61 \%$ of the SAT's audit acts were either reviews of CPA reports (including cross-checking of information) or letters to taxpayers requesting more information, and over 30\% were perfunctory visits to taxpayers.

The SAT's audit presence, based on office revisions as well as visits, averaged $2.84 \%$ over the period 1996-1998, which was quite high in comparative terms for the 
general population of taxpayers. If one only takes into actual field audits, the average annual audit presence for the general taxpayer population was estimated at $2.65 \%$ in 1998, which was very respectable.

The SAT also conducted a receipt verification program, in which taxpayers' obligations to comply with printing and issuance of receipts was monitored. The SAT visited about $2.5 \%$ of taxpayers in 1998 and 1999 and found that on average over $78.5 \%$ were not complying with legal requirements. Of those visited $70.5 \%$ were fined and $7.4 \%$ were ordered closed for a short period of time. The non-compliance rates for receipt regulations in Mexico were similar to the general non-compliance rates in Peru.

The data on Venezuela indicate that SENIAT's audit presence varied from $1.00 \%$ to $2.30 \%$ from 1996 to 1999 for all taxpayers (the average over the period was $1.56 \%$ ). ${ }^{48}$ Removing these audit acts from the calculation, the average audit presence for the period was approximately $0.79 \%$, which is quite low compared with Peru and Mexico. ${ }^{49}$ SENIAT's audit presence for its large taxpayers was considerably higher in 1999, at $6.1 \%$, though considerably lower than Peru's.

The audit findings revealed that roughly $41 \%$ of Venezuelan taxpayers were noncompliant with either the sales, income, or assets tax formal requirements in 1999. Further in-depth audits revealed that about $44 \%$ of taxpayers were also non-compliant with more fundamental aspects of these tax policies. Breaking down the data by large taxpayers showed that they were more compliant than the general taxpaying population in terms of the sales, income, and assets taxes, but less compliant in terms of receipt verification.

Tax administrations were also empowered to close down firms for a limited period of time if firms were found in non-compliance with tax law. Some, like SUNAT, made closures a regular feature of compliance management. Others, like SENIAT and the SAT used closure much less often. The SAT's average closure rate in 1997-1998 was a mere $0.06 \%$. SUNAT, on the other hand, closed an average of $0.75 \%$ of taxpayers (1993-

\footnotetext{
${ }^{48}$ These data, however, include a receipt verification program, which is more properly considered an audit act than an audit.

${ }^{49}$ Assuming that $50.6 \%$ of all audit acts in 1996-1998 were receipt verification, as was the case in Jan.-June 1999.
} 
1994). The temporary closure of non-compliant firms, with the exception of Peru, was sorely underused in these countries.

There was a perception in Kenya that the KRA has contributed to improved tax compliance by being tougher and fairer at the same time. ${ }^{50}$ As one member of the national accountants' professional association put it, "There is more compliance because you expect they (KRA) will come after you and get you at the end of the day." 51 There was a sense that the KRA was "not missing as much as before," due to both improved quantity and quality of audits. ${ }^{52}$ One significant advance was the introduction of field audits; prior to the KRA only desk audits were performed. Compliance visits were also made by KRA staff to business establishments to ensure compliance with certain minimum requirements. The KRA also refined its audit selection procedures to rely less on auditor discretion and more on quantitative indicators, such as gross profit ratios. Audit selection procedures for both income tax and VAT relied on a clearly defined audit checklist. The LTO had a policy of contacting non-filers immediately, creating the impression that taxpayers were under the KRA's microscope.

Audit coverage in the LTO stood at a very respectable rate of $38 \%$. More specifically, LTO VAT audit coverage stood at $40 \%$ while income tax coverage only reached $16 \%$. Of the total amount of audit assessments made in 2001, fully 53\% was collected, while the rest was contested by taxpayers. This was not an inordinately low collection rate, given the problems with tax arrears in Kenya. ${ }^{53}$

The KRA also registered improvement in the audit of non-large taxpayers, specifically regarding the VAT. Though audit coverage of the VAT declined from $9 \%$ in 1999 to $5 \%$ in 2001, reflecting a near 30\% growth rate in registered VAT taxpayers as well as an absolute decline in the number of audits performed, the amount assessed per audit more than doubled, from an average of 1.2 (1997-1998) to 3.0 (1999-2001) million Kshs., representing an improvement in audit quality, even as the number of departmental technical staff fell.

\footnotetext{
${ }^{50}$ Compliance may also have increased due to the lowering of tax rates.

${ }^{51}$ Interview, Nairobi, Kenya, 7/6/2001.

${ }^{52}$ Compliance in the informal sector remains a serious problem.

${ }^{53}$ The payment rate reflects taxpayer perceptions about the ease of holding the tax agency at bay over an extended period of time. If taxpayers believe that it is unlikely that the tax agency has the capacity and resources to pursue the case, and that the court system provides an effective means of resolving disputes to the taxpayer's favor, the actual audit collection rate be low.
} 
SARS established a formal audit policy, which it did not have previously, and reorganized internally to create "compliance centers" that foster teamwork among auditors and between auditors and collections officers. SARS standardized audit processes left less room for individual auditor discretion and provided greater focus for district offices. SARS also introduced integrated audits in $1998^{54}$ and developed an audit strategy that focused more on risk assessment of taxpayers using a new computerized audit tool. SARS research department performed threat and industry analysis to aid in targeting scarce audit resources.

SARS' compliance division, which brought together the audit, investigations, and debt collection units promised to enhance intra-organizational cooperation. In fact, before 1997 the tax administration did not have the capacity to do its own investigative work. With autonomy police and intelligence officials were hired from outside to strengthen SARS capacity in this important area of compliance. SARS prided itself on having won 99 years worth of jail sentences in 2000 and 121 years in 2001 for tax fraud. In addition, SARS attached shares in two companies as securities for taxes owed; these types of measures changed SARS' image and contributed to greater compliance.

SARS's tax assessments issued by auditors also increased. From 2000 to 2001 the value of additional tax assessments issued by auditors grew from approximately $\mathrm{R} 5$ billion to R 6.2 billion, an increase of $24 \%$. Audit yields also increased dramatically, especially in income tax and PAYE, as a result of SARS greater technical and human resource capacity.

Audit coverage, however, declined dramatically, especially in VAT and income tax. As the tax rolls expanded, audit quantity did not kept up. The significant decrease in coverage likely had had a negative impact on tax compliance. It seems clear that SARS reforms did not go far enough, as the organization lacked audit resources, both in terms of the quantity and quality of its staff. Moreover, SARS management was dissatisfied with the overall quality of its audit staff, citing that "the highly competent auditors only form $20 \%$ of the audit staff....

\footnotetext{
${ }^{54}$ SARS' integrated audits have proven to be more productive than the individual tax audit approach. In 2001, the average yield per integrated audit was R 915,000, as compared with the sum of the average audit yield for the VAT, PAYE, and corporate income tax, which was R 101,956 in the same year.

${ }_{55}^{5}$ SARS Annual Report, 2000/2001, p. 39.
} 
The audit function in the URA remained weak in spite of the reform, though the Large Taxpayers Department is better positioned than the rest of the agency. The LTD reported a comprehensive audit presence of about 11\% in 2001 and also reported using third party information to cross-check taxpayer returns (Table 3 summarizes large taxpayer audit coverage across several countries). The Internal Revenue Department registered an audit presence of about $2.6 \%$ in 2001 for filing corporate income tax and VAT taxpayers.

TABle 3. Audit Coverage of LARge TAXPayers

\begin{tabular}{ll}
\hline Revenue Authority & Audit Coverage \\
\hline KRA (2001) & $38 \%$ \\
SENIAT (1999) & $6 \%$ \\
SUNAT (1999) & $11 \%$ \\
URA (2001) & $11 \%$ \\
\hline Source: Author's calculations based on ARA and MOF data.
\end{tabular}

In sum the cases show improvement in taxpayer registration, especially in Peru, Kenya, and South Africa. The cases show that the more autonomous ARAs have invested their resources wisely in their large taxpayers offices. SUNAT and the KRA have focused on their LTOs and have managed to improve performance considerably as a result. SARS has made progress in expanding the tax rolls and improving filing compliance in the income tax. The KRA has also made some progress on expediting refunds. The cases show declining performance in Venezuela and stagnation at best in Uganda. There seems to be a positive association between the greater autonomy of SUNAT, KRA, and SARS, and their relatively better performance.

With respect to compliance management SUNAT has demonstrated progress in comparison to the pre-reform situation, though its performance has not been exceptional in this regard. The Mexican case suggests that while the SAT's performance rates positively in comparative perspective, there has not been much improvement as a result of the reform. Though SENIAT made some progress with its large taxpayers office, the impact of the reform was limited. The KRA made significant progress since the reform, instituting new audit guidelines and procedures, introducing field audits, improving audit productivity, and boosting audit coverage in the LTO significantly, yielding a high 
coverage rate in comparative perspective (see Table 3). SARS also improved its audit function since the reform, establishing a focused audit policy, standardizing audit processes, and improving audit yields. The downside is that SARS audit coverage has declined as the tax rolls have grown. URA performance does not seem to have improved markedly since the reform, though the situation is better in the LTO as compared with the rest of the taxpayer population.

\section{Taxpayer Services}

Several ARAs also made headway in the improvement of taxpayer services, an important yet oft-overlooked function of tax agencies. The cases demonstrate that the more autonomous revenue authorities have been the ones most concerned with improving taxpayer services. Notably, the KRA and SUNAT made significant efforts to improve taxpayer services, though these efforts did not always translated into significantly improved services. SARS initiatives were still too incipient to judge, but the focus on taxpayer services holds promise. SENIAT and the URA made only modest progress.

Though the KRA attempted to make taxpayer service delivery a key element of its reform program, results to date have been less than satisfactory. For example, though the KRA introduced a Taxpayers' Charter, which was intended to provide transparent standards of service for taxpayers and serve as a sign of the authority's interest in making tax compliance easier, observers noted that the charter was not put into practice. ${ }^{56}$ As further evidence of its commitment, the KRA established a VAT customer care help desk in its headquarters office, yet services, especially technical advisory ones, were still regarded as weak. Even the LTO was regarded as having inferior quality taxpayer services. The LTO had difficulty responding promptly and accurately to inquiries. Some reported improvements in KRA forms (tax returns, etc.).

As a result it is probable that KRA's autonomy did not led to reduced compliance costs for taxpayers through better services. In fact, tax professionals argued that because of the KRA's more active, higher quality audit program, compliance costs actually increased as taxpayers saw fit to keep more records, and to do so more accurately. One

\footnotetext{
56 “Taxpayer's Charter: Taxpayers Rights and Obligations,” KRA.
} 
professional from a major tax consulting firm noted that the LTO had been responsible for generating more demand from clients for his firm's services.

The SARS introduced service desks in all larger customs offices and in some larger revenue offices. SARS focused more on taxpayer services by establishing a taxpayer services division under a general manager and regional managers and creating over forty new integrated service centers around the country.

The URA, on the other hand, while it has not been radical in its approach to improving taxpayer services, noted some improvements. Seminars, pamphlets, and radio programs established more regular communication channels with taxpayers and the LTD established a taxpayer service desk. Taxpayers noted an improvement specifically with regard to communication about changes in tax policy and regulations, though taxpayers also complained that the quality of service varied a great deal, depending on the specific tax official, and that it was difficult to get answers to specific questions, indicating a problem with the provision of specific as opposed to generic information. As a result, compliance costs remained high for Ugandan taxpayers.

In Latin America Peru made the most progress on taxpayers services. For example, one stop service offices ("Plaza SUNAT") were established in many of the countries largest cities. In both Peru and Venezuela ARAs focused on improving taxpayer services principally for large taxpayers to the detriment of the vast majority of individual and small business taxpayers. However, both SUNAT and SENIAT were successful in improving basic services for large taxpayers, though to varying extents.

Some survey results illustrate the point. Regarding the reasonableness of the quantity of information required in tax declaration forms, $94 \%$ in Venezuela said it was Somewhat, Fairly, or Very Reasonable, as compared with $93 \%$ in Peru and $42 \%$ in Mexico. With respect to the clarity of new regulations issued by the tax agency, Peruvian taxpayers expressed much greater satisfaction than taxpayers in the other two countries. In terms of the usefulness of tax publications, including guides and manuals, Peru ranked highest while the other two cases ranked much lower. In terms of the ease of obtaining information from the tax agency, 54\% of Peruvian respondents said it was Slightly, Fairly, or Very Easy, as compared with $45 \%$ in Venezuela, and $38 \%$ in Mexico. Regarding the reliability of information given by tax agency officials, $68 \%$ of Peruvians 
said it was Somewhat, Fairly, or Very Reliable, as compared with 58\% in Venezuela, and only $50 \%$ in Mexico. The survey data clearly showed that across the board information services, both in terms of access to information and its quality, were deficient, in spite of the reforms. ${ }^{57}$

Conclusion: Evidence of an Association between Autonomy and Performance

The cases demonstrate that the ARA model permits managers to take greater control over their organizations and manage them more effectively, though they also demonstrate that some ARAs, notably Peru, Kenya, and South Africa (and perhaps Venezuela before SENIAT's autonomy was reduced), were more successful than others in improving their performance (Table 4 presents a summary of performance by indicator and ARA). ${ }^{58}$

TAble 4. ARA Performance: A Summary Comparison

\begin{tabular}{|c|c|c|c|c|c|c|}
\hline & \multicolumn{2}{|c|}{ Input Indicators } & \multicolumn{4}{|c|}{ Output and Outcome Indicators } \\
\hline & $\begin{array}{l}\text { Personnel } \\
\text { Management }\end{array}$ & $\begin{array}{l}\text { Collection } \\
\text { Costs }\end{array}$ & Collections & Registration & Compliance & $\begin{array}{l}\text { Taxpayer } \\
\text { Services }\end{array}$ \\
\hline KRA & $\begin{array}{l}\text { - } \text { Quasi- } \\
\text { voluntary } \\
\text { retrenchment } \\
\text { - Overall staff } \\
\text { reduction } \\
\text { - Selective salary } \\
\text { increase } \\
\text { - Financial } \\
\text { support for staff } \\
\text { training }\end{array}$ & $\begin{array}{l}\text { - Very low } \\
\text { collection } \\
\text { costs }\end{array}$ & $\begin{array}{l}\text { Declining } \\
\text { tax/GDP } \\
\text { ratio with } \\
\text { falling tax } \\
\text { rates (trend) }\end{array}$ & $\begin{array}{l}\text { - Expansion of } \\
\text { tax base, } \\
\text { especially } \\
\text { VAT } \\
\text { - Focus on } \\
\text { large } \\
\text { taxpayers } \\
\text { with some } \\
\text { success }\end{array}$ & $\begin{array}{l}\text { - Improvement } \\
\text { in audit } \\
\text { coverage } \\
\text { - Improved } \\
\text { audit } \\
\text { procedures } \\
\text { - High audit } \\
\text { coverage of } \\
\text { large } \\
\text { taxpayers }\end{array}$ & $\begin{array}{l}\text { - Some } \\
\text { improvement }\end{array}$ \\
\hline SARS & $\begin{array}{l}\text { - Salary increases } \\
\text { - Special } \\
\text { initiatives, } \\
\text { including } \\
\text { performance } \\
\text { bonuses } \\
\text { - Slight reduction } \\
\text { in staff } \\
\text { complement } \\
\text { - Excellent } \\
\text { training } \\
\text { opportunities }\end{array}$ & $\begin{array}{l}\text { - Very low } \\
\text { collection } \\
\text { costs }\end{array}$ & $\begin{array}{l}\text { - Relatively } \\
\text { stable } \\
\text { tax/GDP } \\
\text { ratio with } \\
\text { declining tax } \\
\text { rates }\end{array}$ & $\begin{array}{l}\text { - Across the } \\
\text { board } \\
\text { expansion of } \\
\text { tax base } \\
\text { - Mixed results } \\
\text { with filing } \\
\text { compliance }\end{array}$ & $\begin{array}{l}\text { - Improved } \\
\text { audit } \\
\text { procedures } \\
\text { - Increased } \\
\text { audit } \\
\text { productivity } \\
\text { - Declining } \\
\text { audit } \\
\text { coverage }\end{array}$ & $\begin{array}{l}\text { - Improvements } \\
\text { planned }\end{array}$ \\
\hline URA & $\begin{array}{l}\text { - Periodic salary } \\
\text { increases } \\
\text { - Increase in staff } \\
\text { complement }\end{array}$ & $\begin{array}{l}\text { - High } \\
\text { collection } \\
\text { costs }\end{array}$ & $\begin{array}{l}\text { - Substantial } \\
\text { increase in } \\
\text { tax/GDP } \\
\text { ratio }\end{array}$ & $\begin{array}{l}\text { - Focus on } \\
\text { large } \\
\text { taxpayers } \\
\text { with little } \\
\text { success }\end{array}$ & $\begin{array}{l}\text { - Moderate } \\
\text { audit } \\
\text { coverage of } \\
\text { large } \\
\text { taxpayers }\end{array}$ & $\begin{array}{l}\text { - Some } \\
\text { improvement } \\
\text { for large } \\
\text { taxpayers }\end{array}$ \\
\hline SAT & 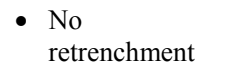 & $\begin{array}{l}\text { - Low } \\
\text { collection }\end{array}$ & $\begin{array}{l}\text { - No major } \\
\text { change }\end{array}$ & $\begin{array}{l}\text { - No major } \\
\text { progress }\end{array}$ & $\begin{array}{l}\text { - No major } \\
\text { change }\end{array}$ & $\begin{array}{l}\text { - Some } \\
\text { improvement }\end{array}$ \\
\hline
\end{tabular}

${ }^{57}$ Taliercio (2000, 339-341).

${ }^{58}$ A recent IMF report (2003: 100) cites Ecuador as a good example of the positive impact of autonomy on tax administration performance. 


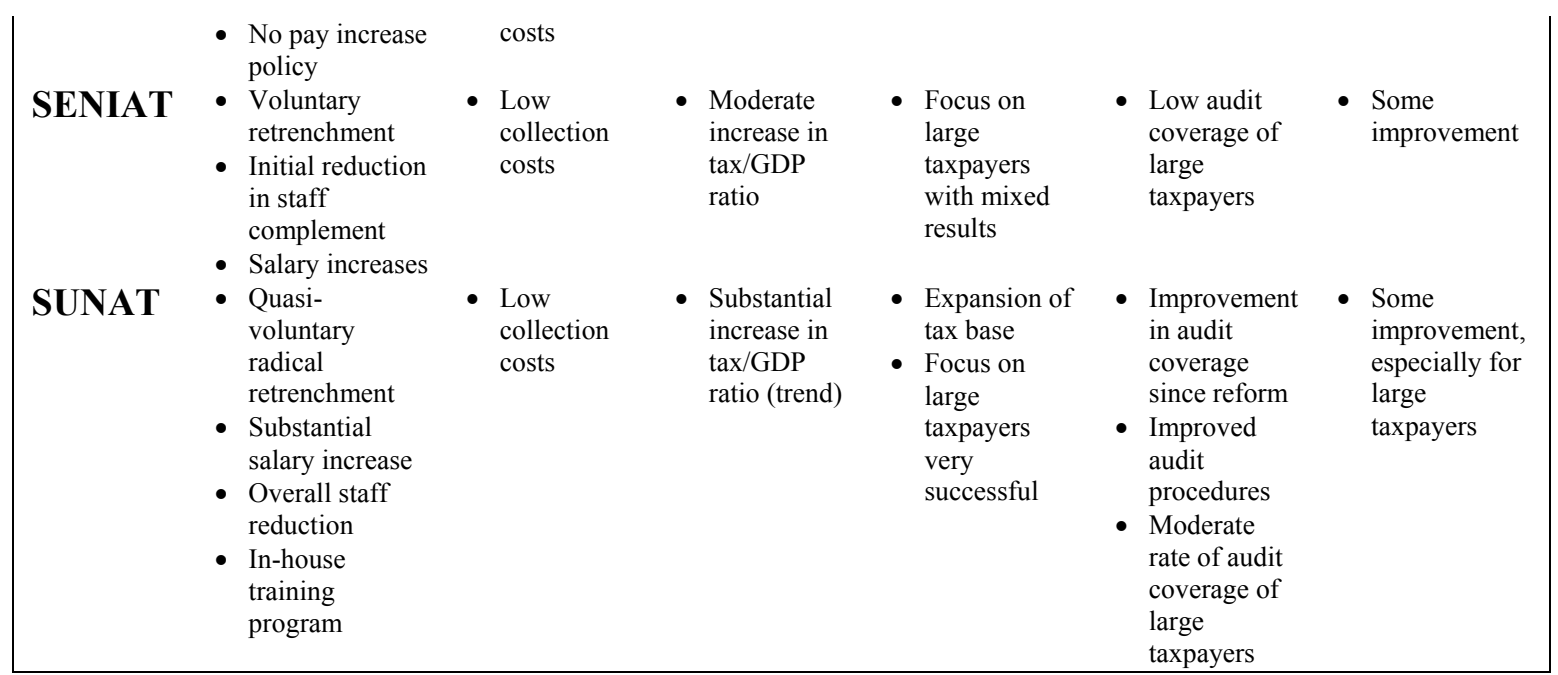

What accounts for the difference? The cases suggest an association between improved performance and greater autonomy. Simply put, ARA managers with greater autonomy were able to take reforms farther and faster than those with less autonomy. The issue of competent management seems not to have been the binding constraint; most cases demonstrated the presence of effective management. Yet when managers' hands were tied by low autonomy, there was less they could do. Thus, the cases suggest that autonomy itself, rather than effective management, is the binding constraint.

At the same time greater autonomy reduces micromanagement in tax administration matters by ministries of finance, which, on the whole, seems to be a positive outcome. Greater autonomy also reduces political interference, which is undoubtedly a positive outcome.

This is not to say that autonomy was absolutely necessary for these changes to take place. There may have been other ways to achieve them. However, in interviews in Latin American and Africa, ARA managers repeatedly stressed the importance of being able to make decisions more quickly and manage their organizations more flexibly responsively as a result of their additional autonomy. For instance, KRA managers report that their autonomy has enabled them to take more effective control over personnel management by confidently resisting pressure to make staff decisions based on political calculations. There is clearly a sense that managers in ARAs feel more empowered than they did under the previously existing organizational structure, though many opined that they could be even more effective if they had greater managerial autonomy. Thus, though 
autonomy may not be necessary for certain administrative reforms, such as the creation of large taxpayers departments, it most likely enhances the effectiveness of these reforms (there are countries in which large taxpayers departments were created, yet in the absence of greater administrative autonomy, have yielded little in the way of improved performance). ${ }^{59}$

The greater flexibility afforded by the ARA design is increasingly important in the increasingly complex environment faced by tax agencies. ${ }^{60}$ Over the past dozen years there have been three major factors challenging developing country tax administrations: (1) economic growth, (2) globalization, and (3) technological change. Bahl and MartínezVazquez argue that economic modernization means that "the job of tax administration will become more and more complex...(1992:107).” James and Wallschutzky (1995) argue that economic growth in itself has a powerful effect on the ability of a tax administration to perform its statutory tasks. They suggest that as wealth increases, taxpayer "sources of income will increase in both number and complexity (210)." In terms of the individual income tax, for example, in the presence of economic growth, families move from having just one major source of income to having several sources. Consequently, taxpayers become more differentiated from one another across time and space.

It is clear that the past decade or so has produced enormous change in the way tax administrations need to operate. From economic growth to globalization to new technologies, the environment of tax administrations has changed substantially. Economic growth has increased taxpayers' occupational and geographical mobility while also increasing the sheer number of taxpayers. Growth has also made more numerous and diversified the sources and types of taxpayers' incomes. With higher taxpayer mobility and greater numbers of taxpayers, the tax administration is more uncertain about whether taxpayers are escaping the tax net as the problems of non-filing and stop-filing become more acute. With more numerous sources of income, the tax administration is more uncertain about whether it is assessing taxes on the total earned income of the taxpayer.

\footnotetext{
${ }^{59}$ This is not to say that political support was not instrumental in making both autonomy (in the first place) and improved performance possible. Indeed, the import of political support for sustainable reform is the subject of Taliercio (2004b).

${ }^{60}$ See Taliercio $(2000,14-23)$ for a fuller discussion.
} 
Underreporting of income becomes more problematic as well. Growth has also made private sector employment more attractive relative to the public sector, drawing away experienced professionals from tax administration.

At the same time, globalization of markets has meant more open borders and greater private capital inflows. World and regional trade agreements have lowered trade barriers, thus reducing tax revenues and challenging the mission of customs departments. Dealing with many large, modern multinational corporations poses tough new challenges for tax administrators. The issues are numerous and vastly complicated, from off-shore tax havens to double taxation agreements to transfer pricing to taxation of new financial instruments (see, for example, Tanzi, 1995). Many developing country tax administrations are not equipped with the resources necessary to deal effectively and efficiently with the taxation of multinational corporations. ${ }^{61}$

A technological revolution has also occurred in the past decade with regard to the availability of personal computers and more specialized software. Unfortunately, however, the public sector in many developing countries has not yet been able to take advantage of the new technology. That the private sector has been able to take advantage means that the capacity gap between tax administrations and its clients has grown. It is for all of these reasons that tax administrators argue that the greater flexibility afforded to them by the ARA design is important for their overall success.

The nature of the autonomy granted to revenue authorities has, by design, been limited, which has caused some problems for managers. A central issue is the extent to which autonomy can insulate tax agencies from negative political influences. The most deleterious interference is associated with political patronage, and ARAs have had varying degrees of success fending off patronage-based pressure.

Other types of political pressure can also have a negative impact. In the case of the URA, for example, there has been pressure from higher levels of government to meet collection targets, resulting in disproportionate emphasis on tax collections over other organizational goals, such as improved taxpayer services. Autonomy has not been able to insulate ARAs from undue pressures that interfere with good management.

\footnotetext{
${ }^{61}$ The issue here is not simply whether the tax administration can prevent tax evasion, but whether the tax administration can offer the services necessary to reduce taxpayer compliance costs in an increasingly competitive world.
} 
Lastly, in addition to the performance indicators assessed here, survey data have also shown that corporate taxpayers in Latin America associate higher levels of autonomy with higher levels of performance. ${ }^{62}$ That is, perceptions of higher levels of autonomy are associated with perceptions of better performance along key dimensions of administrative capacity in tax administration. These results, along with the objective performance indicators discussed in this section, provide support for the contention that semiautonomous revenue authorities are mechanisms to promote credible political commitments to reform in developing countries.

\section{ORGANIZATIONAL DESIGN: HOW DOES AUTONOMY MATTER?}

The ARA reform model is a set of organizational features designed to enhance managerial and bureaucratic autonomy. Some features focus on general management, while others address financial or personnel autonomy. As the elements of bureaucratic autonomy are intertwined, the design features are inherently multifunctional, which means that a particular feature will have an impact on multiple dimensions of the organization's autonomy. For example, greater financial autonomy, in addition to providing greater control over the use of resources, has the effect of increasing autonomy over personnel management.

The fact that the ARA model is actually a bundled set of reforms has three implications. First, there are many ways that an agency can be made more autonomousthere are a number of variations on the basic model. One agency might have more financial autonomy while another might have greater autonomy with respect to corporate governance. There is no set accepted best practice. Second, the impact of each particular design element cannot be easily isolated from the whole and evaluated rigorously on its own. This implies that an evaluation of each individual element must be analyzed ceteris paribus. Third, given the plethora of design options and the difficulty in evaluating both each feature individually and the set of features taken as a whole, controversies have arisen over specific organizational characteristics that these agencies should have. The purpose, then, of this section is to set out the main issues in the organizational design of semi-autonomous revenue authorities and, based on country experience, offer hypotheses

${ }^{62}$ Taliercio, 2001a. 
about which design options work better than others and why. That is, if autonomy matters, as the previous section argues, how exactly does it matter?

Semi-autonomous revenue authorities are defined as tax administrations that have greater than usual autonomy along several organizational design dimensions, including: legal character, corporate governance, financing and budgeting, personnel policy, procurement policy, and accountability relationships. Each subsection makes recommendations (in box form), based on the experience of the countries under study, for increasing organizational autonomy, based on the argument that autonomy has been shown to improve performance. The recommendations point to the key design issues that must be resolved if the organization is to have effective managerial autonomy.

In addition the section analyzes how managers from the country cases have used these features to promote substantive administrative reform. In discussing management's utilization of these reforms, initiatives are framed in the context of whether they could have been undertaken without autonomy. That is, an attempt is made to gauge the real impact of autonomy on reform by making judgments about the contribution of autonomy to reform, separate from, say, good management or exogenous factors. The intention of this section is to develop a series of hypotheses based on the cases that take seriously the issue of organizational design, especially given that previous work on tax administration reform has not treated these questions with any analytical depth.

\section{$\underline{\text { Legal Foundations }}$}

National governments have different legal forms they can use to create more or less autonomous agencies, according to their constitution and legal tradition (see Table 5). SUNAT is a decentralized public organization, while SENIAT is an autonomous institute. The South Africa Revenue Service (SARS) is a public sector organization outside the public service, while the Kenya Revenue Authority (KRA) is a corporate body exempt from the State Corporations Act. The seemingly contradictory language used to describe the nature of ARA autonomy in some cases reflects actual contradictions and ambiguities in the legal design of these semi-autonomous agencies. 
TABle 5. Legal CHARACTERISTICS

\begin{tabular}{|c|c|c|c|c|c|c|}
\hline & Foundation & Form & Character & Patrimony & Creation & $\begin{array}{l}\text { Type of } \\
\text { Autonomy }\end{array}$ \\
\hline \multicolumn{7}{|c|}{ Africa } \\
\hline KRA & $\begin{array}{l}\text { KRA Act } \\
(1995)\end{array}$ & $\begin{array}{l}\text { Corporate body } \\
\text { with perpetual } \\
\text { succession }\end{array}$ & $\begin{array}{l}\text { Separate } \\
\text { legal } \\
\text { character }\end{array}$ & $\begin{array}{l}\text { Can own } \\
\text { assets }\end{array}$ & $\begin{array}{l}\text { Parliamentary } \\
\text { Act }\end{array}$ & Unspecified \\
\hline SARS & $\begin{array}{l}\text { SARS Act } \\
(1997)\end{array}$ & $\begin{array}{l}\text { Revenue service } \\
\text { outside the public } \\
\text { service but part } \\
\text { of the public } \\
\text { administration }\end{array}$ & $\begin{array}{l}\text { Separate } \\
\text { legal } \\
\text { character }\end{array}$ & $\begin{array}{l}\text { Can own } \\
\text { assets }\end{array}$ & $\begin{array}{l}\text { Parliamentary } \\
\text { Act }\end{array}$ & Administrative \\
\hline URA & $\begin{array}{l}\text { URA Act } \\
(1991)\end{array}$ & $\begin{array}{l}\text { Corporate body } \\
\text { with perpetual } \\
\text { succession }\end{array}$ & $\begin{array}{l}\text { Separate } \\
\text { legal } \\
\text { character }\end{array}$ & $\begin{array}{l}\text { Can own } \\
\text { assets }\end{array}$ & $\begin{array}{l}\text { Parliamentary } \\
\text { Act }\end{array}$ & Unspecified \\
\hline \multicolumn{7}{|c|}{ Latin America } \\
\hline SAT & $\begin{array}{l}\text { SAT Law } \\
(1995)\end{array}$ & $\begin{array}{l}\text { Deconcentrated } \\
\text { service }\end{array}$ & $\begin{array}{l}\text { No separate } \\
\text { legal } \\
\text { character }\end{array}$ & $\begin{array}{l}\text { Can own } \\
\text { assets }\end{array}$ & $\begin{array}{l}\text { Legislative } \\
\text { Law }\end{array}$ & $\begin{array}{l}\text { Management, } \\
\text { budgetary, and } \\
\text { technical }\end{array}$ \\
\hline SENIAT & $\begin{array}{l}\text { SENIAT } \\
\text { Decree } \\
(1994)\end{array}$ & $\begin{array}{l}\text { Autonomous } \\
\text { service }\end{array}$ & $\begin{array}{l}\text { No separate } \\
\text { legal } \\
\text { character }\end{array}$ & $\begin{array}{l}\text { Can not } \\
\text { own assets }\end{array}$ & $\begin{array}{l}\text { Presidential } \\
\text { Decree }\end{array}$ & $\begin{array}{l}\text { Functional and } \\
\text { financial with } \\
\text { its own human } \\
\text { resource } \\
\text { system }\end{array}$ \\
\hline SUNAT & $\begin{array}{l}\text { SUNAT Law } \\
(1988)\end{array}$ & $\begin{array}{l}\text { Decentralized } \\
\text { Superintendency }\end{array}$ & $\begin{array}{l}\text { Separate } \\
\text { legal } \\
\text { character }\end{array}$ & $\begin{array}{l}\text { Can own } \\
\text { assets }\end{array}$ & $\begin{array}{l}\text { Legislative } \\
\text { Law }\end{array}$ & $\begin{array}{l}\text { Functional, } \\
\text { economic, } \\
\text { technical, } \\
\text { financial, and } \\
\text { administrative } \\
\end{array}$ \\
\hline
\end{tabular}

Source: ARA laws, acts, and decrees.

The legal foundation of a ARA defines three important dimensions of autonomy: its corporate nature, the ability to own assets, and the nature of its legal underpinnings. The corporate status of an ARA depends fundamentally on whether or not it has its own separate legal character. ARAs generally have their own separate corporate status (see Table 5). ARAs without their own corporate character are inherently less autonomous, as shown by the Mexican and Venezuelan cases. Though the impact of not having a separate corporate character may not necessarily be experienced as problematic by management on a day to day basis, the issue takes on great importance when disputes and ambiguities arise over the nature of the ARA's autonomy. Agencies without their own corporate identity are ultimately subject to greater control by external actors.

Legal Foundation Issue 1: To bolster autonomy ARAs should have their own separate corporate character as defined by national law.

The right to own assets is also an important determinant of autonomy. ARAs that can own assets are more autonomous in that they are less dependent on the MOF for the 
use of physical infrastructure, IT systems, and supplies. The right to own assets also affords ARAs greater flexibility and predictability in managing their resources. Most ARAs can own assets. SENIAT, however, is dependent on the MOF for permission to use assets and is subject to ministerial decisions to revoke use rights or reassign assets within the ministry. The lack of basic property rights weakens the managerial autonomy of the ARA and subjects it to uncertainty in the use and availability of physical assets.

Legal Foundation Issue 2: To strengthen autonomy ARAs should have the right to own assets.

The legal framework of the ARA also defines its place in the hierarchy of public administrative law. In some cases ARAs are granted blanket exemptions from public administrative law pertaining to staff benefits and procurement, among other things. In the case of Kenya the KRA is exempt from the State Corporations Act, which means that the tax agency has autonomy over a whole series of administrative issues. In the case of Uganda, however, the URA is not exempt from government-wide regulations. On the contrary, the authority is defined as an agency of government under the "general supervision" of the minister of finance. The fact that the URA is not exempt from government-wide civil service regulations has led to problems implementing reform measures. In South Africa SARS is defined as "an organ of state within the public administration, but as an institution outside the public service." 63 The distinction concerns the fact that though SARS is a public organization it is not part of the civil service.

Legal Foundation Issue 3: To make autonomy effective the ARA should be exempt from specific government-wide regulations, including civil service regulations. ARAs might also be exempted from government-wide procurement regulations.

The legal foundation of ARAs varies from an act passed by the legislature or parliament to a decree promulgated by a president or minister. Most ARAs are founded on a legislative or parliamentary decree, which means that the legislative branch of government has been involved in most fundamental reform tax agency reforms. This

\footnotetext{
${ }^{63}$ SARS went through a two-staged reform process. First, in June 1996, customs and inland revenue, which were part of the MOF, were set up as a separate, unified ministry (the SARS Department) under a CEO, as an interim arrangement on the way to a revenue authority. In September 1997 the SARS became an ARA.
} 
would seem to offer something of a buffer against political winds, as it may be more difficult to reverse ARA reform if more than one branch of government is involved.

Legal Foundation Issue 4: To safeguard autonomy the ARA's legal foundation should be based on legislative, not executive, authority.

With the exception of the Venezuelan case, there is a high degree of convergence among ARAs around foundational legal design issues (there is even more intra-regional convergence). This basic legal question is thus largely uncontroversial. Most ARAs are endowed with the basic elements of autonomy that flow from their legal foundations, which is appropriate given that without the basics more sophisticated design features become much less meaningful. It would seem that these basic elements-independent corporate identity and the right to own assets - are indispensable for building some degree of autonomy. At a minimum ARAs ought to be founded in legislative or parliamentary law, have independent corporate identities, and be able to own assets. These basic features provide a sound foundation upon which meaningful autonomyenhancing features may be constructed, which may explain why they are largely uncontroversial.

The one legal design issue that is somewhat controversial, however, concerns the position of the ARA vis-à-vis public administrative law. In order for the authority to gain a measure of autonomy, it should be exempt from some government-wide regulations concerning personnel, and perhaps procurement. For autonomy to be meaningful, the ARA should have the ability to design its own systems to substitute for government-wide ones. Moreover, if the authority's legal foundation is silent on these questions, ambiguity about its relation to the greater public sector will arise sooner or later. This type of legal ambiguity would be best to avoid, as it calls into question the nature of the authority's autonomy.

\section{Corporate Governance}

ARAs are characterized by two general governance models: a chief executive officer (CEO) model, used only in Latin America, and a board of directors model, used 
mostly in Africa and Asia (see Table 6). ${ }^{64}$ There are fewer variations among CEO-based models and board-based models. The main organizational design difference observed within CEO-based models is the appointment of the CEO.

Table 6. Governance Structure

\begin{tabular}{|c|c|c|}
\hline & $\begin{array}{l}\text { GOVERNANCE } \\
\text { MODEL }\end{array}$ & COMPOSITION AND APPOINTMENT \\
\hline KRA & Board of Directors & 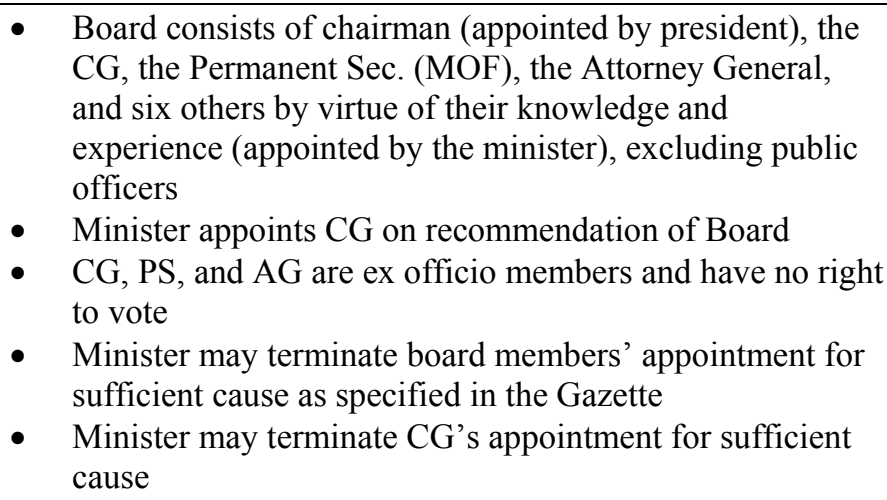 \\
\hline SARS & Advisory Board & $\begin{array}{l}\text { Board consists of up to eight persons (appointed by } \\
\text { minister of finance), the commissioner, and up to two } \\
\text { senior SARS employees (named by commissioner) } \\
\text { Minister of finance appoints commissioner after } \\
\text { consulting with cabinet and advisory board }\end{array}$ \\
\hline URA & Board of Directors & $\begin{array}{l}\text { Board consists of chairperson (appointed by the minister), } \\
\text { one representative of the MOF, one representative of the } \\
\text { ministry of trade and industry, one representative of the } \\
\text { Uganda Manufacturers Association, the CG, and two } \\
\text { others by virtue of their knowledge and experience in } \\
\text { taxation (appointed by the minister), excluding public } \\
\text { officers } \\
\text { - Minister appoints CG on recommendation of Board }\end{array}$ \\
\hline \multicolumn{3}{|r|}{ Latin America } \\
\hline SAT & Board of Directors & 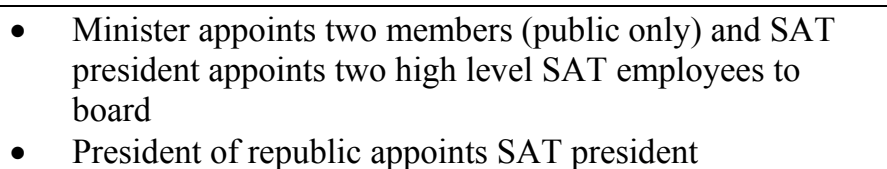 \\
\hline SENIAT & Superintendent & $\begin{array}{l}\text { - Minister appoints superintendent and adjunct } \\
\text { - } \quad \text { Minister may remove superintendent }\end{array}$ \\
\hline SUNAT & Superintendent & $\begin{array}{l}\text { - President of republic appoints and removes } \\
\text { superintendent on suggestion of minister of finance }\end{array}$ \\
\hline
\end{tabular}

Source: ARA laws, acts, and decrees.

\footnotetext{
${ }^{64}$ The Mexican and Guatemalan cases are the only Latin American ARAs that use the board of directors model, while the South African case is the only one in Africa that uses an advisory board instead of a board of directors.
} 
The governance structure, which determines to a large extent the effective level of autonomy, is perhaps the most basic issue of organizational design. The key issue is the role of the MOF. Structures in which the minister of finance dominates the governance process yield less autonomy. Another issue is whether there should be private sector representation on the board, and, if so, whether private sector positions should be fixed in the legislation or depend on the discretion of the minister. In addition, whether the CEO should be appointed to a fixed term, as in Malawi and Guatemala, is another important design issue. ${ }^{65}$

The role and design of the board of directors is potentially one of the most important organizational features of the ARA. The role of the board should be to provide guidance on the overall management of the agency, not to engage in the administration of the ARA. There are five key design issues: (1) the role of the president and minister of finance with respect to board appointments and dismissals, (2) fixed appointments, including ex officio members, (3) the nature of tenure on the board, (4) the role of private sector representatives, and (5) decision making mechanisms on the board.

\section{Political Control over the Board}

The first issue is the nature and extent of control of the president and minister of finance over the board of directors. The chairperson of the board is typically either appointed by the president or the minister. In many cases the chair does not serve a fixed term and is not approved by the legislature. Given the existence of a board of directors, the position of the chairperson is paramount. The degree of autonomy of the chair has a direct impact on the degree of autonomy of the ARA. As such, it is preferable that the chair be more rather than less autonomous. The chair should thus report directly to the president, who should be responsible for appointing and removing him. In addition, to augment the chair's credibility and increase the chances that the chair is not seen as politically dependent on the government, the chair should be appointed to a fixed term subject to removal only for pre-specified reasons and his appointment should be approved by the legislature. Though the minister of finance would play an informal advisory role, it

\footnotetext{
${ }^{65}$ In Guatemala, the revenue authority's CEO is approved by the congress.
} 
would be preferable that he not play a direct role in appointing or removing the chairperson of the ARA board.

Corporate Governance Issue 1: To strengthen autonomy the chairperson of the board of directors should be appointed by the president, approved by the legislature, and subject to a fixed term of service.

\section{Board Composition: Ex Officio Members}

ARAs have approached the issue of board composition quite differently. Some, like Kenya and Mexico, allow the minister a free hand in naming and removing appointees. Others, like Uganda and Malawi, specify board positions to be filled by individuals in certain positions. Almost all ARAs, however, use some fixed positions to determine board composition, though in many cases these positions are ex officio. In the Kenyan case three government representatives sit on the board, though they are ex officio and thus cannot vote. As most ex officio positions are governmental, using them as fixed positions establishes a line of communication between the ARA and other government departments, but does not allow those other entities to dominate board decision making. In some cases ex officio members are quite powerful individuals, viz. the Permanent Secretary of the MOF (PS-MOF). Installing these powerful public sector representatives on the board as voting members might create an imbalance, giving too much influence to other public sector entities, namely the MOF. Allowing for institutionalized representation of the MOF on the board in an ex officio capacity provides for a formal line of communication without allowing the MOF to micromanage, and perhaps dominate, the board.

Corporate Governance Issue 2: Public sector representatives on the board of directors should serve in an ex officio (i.e., non-voting) capacity to increase revenue authority autonomy. 


\section{Board Composition: Private Sector Members}

The use of non-ex officio fixed positions has two effects. First, it limits the influence of the minister of finance on the board for the simple reason that she is not empowered to appoint the entire board. Second, it institutionalizes the influence of certain interest groups, whether the civil service, government ministries, professional associations, or economic groups. It may establish a center of power on the board that is more autonomous from the MOF in particular and the government in general. The potential benefits of establishing fixed positions with voting rights are greater autonomy for the ARA and the guarantee that interests affected by the tax agency will have input into how the agency is managed. The first potential benefit applies whether the fixed position is in the public or private sectors. The point is that these board members are not necessarily beholden to the MOF or the government (though if they are appointed by the government they may well represent the interest of the appointing authorities).

The second potential benefit accrues largely to the tax agency's main constituents: taxpayers. There are a number of arguments for having representatives of taxpayers on the ARA board. For one taxpayer representatives can provide invaluable information to the agency on compliance and corruption costs faced by taxpayers. Taxpayer representatives could easily and reliably identify critical bottlenecks and problems in tax administration. They could also suggest solutions, based on their private sector experience. That is, taxpayer representatives would eliminate the asymmetric information problem that exists between the tax agency and themselves.

Private sector representatives on the board could also help free the tax agency from negative political influences. Private sector representatives could monitor the ARA with an eye to detecting and uncovering politically motivated actions and corruption. As presumably independent of the government, private sector board members could credibly oppose political interference, as in the Kenyan case (see Taliercio, 2003b), and offer support for professional administration. If they occupied fixed positions, they could do so without fear of reprisal as their tenure on the board would not be subject to discretionary removal by the government.

However, there are potential costs to the inclusion of private sector representatives on the board: there is a danger of a conflict of interest (see Jenkins, 1994). 
This problem would materialize if a private sector representative were more interested in using his/her position to obtain private benefits than to advise on making tax administration more effective and fair. This potential cost might be more likely to occur if the board member were representing specific economic interests as opposed to a professional group. This potential cost could be mitigated through the use of conflict of interest provisions in the ARA's founding legislation, coupled with a vigilant board.

Moreover, in the cases with private sector representation of the board, there have not been any documented public cases of conflict of interest problems, though there have been allegations of problems in both Uganda and Kenya. In Uganda some hold the perception that the Uganda Manufacturers' Association (UMA) unfairly uses its position on the URA board to lobby for measures that favor the manufacturing sector. Whether these allegations are true or not, they do damage the credibility of the tax agency. Representatives of private sector professional associations, such as accountants and attorneys, are less susceptible to charges of conflict of interest and may also have the broader vision of the tax system necessary for adding value to the board's decision making processes.

Another potential cost is that the tax agency would lose its ability to act strategically. As the private sector will presumably know the compliance strategy of the agency, it loses the benefit obtained from private sector uncertainty about, say, the audit rate. However, if the agency's compliance program is effective, this should not be a major concern.

The role of private sector representatives on the board would depend to some extent on the level of development of private sector organizations and the larger relationship between the government and the private sector. If private sector organizations and professional interest groups are cohesive, their impact on the board might very well be salutary. If private sector organizations are beholden to an authoritarian government, their representation on the board will do little to generate autonomy.

There are two ways to place private sector representatives on the board. The minister may be free to appoint them, as in the Kenyan case, or they may be fixed in the legislation, as in the Ugandan case. Having them fixed in law is more credible because 
they are more likely to be freer from governmental influence. The minister, if free to appoint them, may revert to appointing former colleagues, as in the Kenyan case, which might not always be the best approach. If a board of directors is thought necessary, it follows that a board that is not handpicked by the minister of finance is also necessary.

What the cases show is that in Kenya, in which the board had some autonomy, private sector representation seemed to reinforce that autonomy. In Uganda, on the other hand, in which the board was weaker, private sector representation did not seem to have much of an impact. In South Africa, in which the board has an advisory role only, representatives from reputable private sector organizations bolstered the credibility of the board and thus the SARS.

Corporate Governance Issue 3: Private sector representatives from reputable professional associations and business groups, whose positions are fixed in the legislation, can bolster ARA autonomy by insulating it from negative political interference.

\section{Board Tenure and Appointment}

The third issue is the nature of tenure on the board. In most countries tenure is loosely specified. Provisions for appointment and dismissal grant the minister of finance a great deal of discretion. If board members do not have some security of tenure, however, their ability to provide independent guidance might be compromised. In fact, in Kenya board members have been fired en masse over disagreements with the government. Security of tenure is thus an indispensable element of board autonomy. The exact provisions would vary from country to country, but at a minimum board members should be appointed for fixed terms, subject to removal only for malfeasance or incapacitation. Moreover, consideration should be given to requiring that dismissal of the chairperson be subject to the approval of the legislature. Strong tenure provisions would not only protect members but would provide incentives to the government to take the appointment process very seriously. Equally important is the nature of board appointments. Subjecting them to approval by the legislature, as in Guatemala, can help reduce political partisanship and improve the credibility of the organization.

Corporate Governance Issue 4: To protect autonomy board members should be appointed to fixed terms. To enhance accountability board members should be nominated (multiple nominees per position) by the MOF and appointed by the legislature. 
The final design issue is the decision making process on the board. Most boards operate under a simple majority-based voting system. In the event of a tie vote, many acts provide the chairperson with the tie-breaking vote.

\section{Contentious Autonomy: Governance in Practice}

Taken together, the features described above determine how meaningful revenue authority is in practice. A comparison of way boards have operated in practice in the Kenyan, Ugandan, South African, and Mexican cases shows how board design can have an important impact on reform outcomes (see Box 2). The Ugandan, Kenyan, South African, and Mexican cases raise an interesting question about the role of the board of directors and its relationship with the MOF. The cases show that the SARS board, because of its advisory nature, and the URA and SAT boards, because of their dominance by the MOF, have added little value to the ARA reform process. The KRA board, on the other hand, has played a much more important, and in some cases catalytic, role in the reform. Thus, boards with some degree of autonomy have played a much more useful role than boards with little or no autonomy at all. On one level the point is obvious: why create a board of directors dominated by the MOF if the point of the reform is to create a different kind of tax agency?

\section{Box 2. Managing Autonomy: Boards of Directors in Africa and Latin America}

Compared to Uganda, the Kenyan model uses a stronger board of directors, the chairperson of which is appointed by the president while the other six member are appointed by the minister of finance. Neither the chairperson nor the other six members may be public officials. The chairperson can be dismissed by the president unconditionally while the other board members can be dismissed by the minister for specific reasons cited in the act, or for other sufficient cause, which the minister must specify in the public record. ${ }^{66}$ The requirement that the minister publicly specify the cause for dismissal is intended to protect board members from undue political interference.

The design of KRA's board purposely limits the extent of government involvement in the management of the authority by allowing full voting membership for only non-public officials. The design also, however, grants a great deal of power to the minister, who appoints and dismisses the private sector board members. The design thus has the contradictory tendencies of empowering the private sector members on the one hand and empowering the minister of finance on the other hand. The intent seems to be to produce a board that is responsive directly and exclusively to the minister and the president (through the chairperson), and insulated from other public sector influence. However, given the power of the minister to configure the board to his liking, the board will ultimately reflect the preferences and goodwill of the minister, the intention of the law notwithstanding.

${ }^{66}$ Revisions to the KRA Act were made in 1998. As a result the composition and structure of the board was changed substantially. 
Another important aspect of autonomy is the tenure of the board chairperson, board members, and the CG. The tenure of KRA board chairmen has averaged only 1.6 years from $1995-2001^{67}$, though the act allows the chair, like the other members, to serve a maximum of two three-year terms. The fact that the KRA board has had four chairmen in six years raises questions about security of tenure. Board members (excluding chairmen and ex officio members) have fared better, averaging 2.8 years per person-term. Several have even been reappointed after finishing a first term. However, they still fall somewhat short of the minimum three year term. The KRA's CG is also appointed by the minister. The KRA has had four CGs since 1995, the first three of whose terms averaged 1.8 years. ${ }^{68}$ Moreover, three of the four CGs have had previous government experience; only one came from the private sector without any prior government experience.

The data indicate a high rate of turnover for chairmen and a relatively high rate for board members, which suggests that board membership is not characterized by security of tenure. Both the president and the minister have a relatively free hand in determining board membership and they appear to use it liberally. No board members were removed since the public disclosure provision was added to the act in 1999 (as of mid-2001), though it is unknown whether this can be attributable to the provision.

The relatively high turnover rate of board chairpersons and members would seem to indicate that both the autonomy of the board and the CG are unstable. The KRA design thus provides some modicum of autonomy, but due to the contradictory tendencies of the appointment and removal features, the autonomy is not absolute in practice.

The URA board of directors is composed of several government representatives, one private sector representative, and several members appointed by the minister. The ex officio government members are representatives of the MOF and the ministry of trade and industry; the CG also sits on the board. The private sector representative is from the Uganda Manufacturers Association (UMA). In addition, the minister is authorized to appoint the chairperson and two other members who are not public officers.

The URA board is designed to be squarely under the control of the minister of finance. The composition of the board is such that the minister appoints five of its seven members, including the chairperson and the CG. Board appointees can be initially appointed for a maximum of three years, but can be renewed for an additional three year period. Board members, including ex officio members, can be dismissed by the minister, however, for reasons of malfeasance or incapacitation, or "for any other sufficient cause," according to the URA act. The problem is that there is no mechanism for interpreting what constitutes sufficient cause; presumably, the minister would make this interpretation. This clause effectively means that board members do not have security of tenure. Moreover, the act stipulates that "the minister may give directions to the board regarding the performance of its functions and it shall be the duty of the board to comply with those directions." ${ }^{69}$ The design of the board thus makes it an instrument of ministerial control.

Membership on the first board (September 1991-September 1997) was nominally quite stable. The appointed members, though not public officers, did have political backgrounds or connections, making the entire board membership public sector-related. According to one senior MOF official, the board is "weak" because it is more political than technical. According to another official, the board needs to be "professionalized" even more. By all accounts, the current board (2001) has not been very active (for example, it has not established staff or finance committees). A former URA commissioner regards the board as a "rubber stamp." The board's inactivity may reflect the fact that the MOF has full control of the board, both in terms of the numbers (a majority of MOF-appointees) and in appointing "political" as opposed to "technical" members.

The design of the URA board is such that as a mechanism of corporate governance it is completely dominated by the MOF. Given MOF control of the board, one may question the board's value added. Even with MOF control of the board, a professional, technical board could still be useful for imparting guidance and advice. However, if the board is more political than technical, this potential benefit goes unrealized. The result is that the URA board, as currently configured, serves no useful purpose. Its lack of independence has vitiated its role in the governance of the URA. Given that the board has the potential to be the most important reinforcement of URA's autonomy, it is thus understandable that URA's autonomy in practice has been quite limited. According to a senior member of parliament, who worked on the reform

${ }^{67}$ KRA internal memorandum to World Bank staff, 7/5/01.

${ }^{68}$ KRA internal memorandum to World Bank staff, 7/5/01.

${ }^{69}$ Uganda Revenue Authority Statute, 1998 (1991), Section 5 (4). 
of the URA statute, "The independence of the URA is doubtable. There is a lot of political interference, although by law it's supposed to be independent." "70

The URA statute also provides for a CG, appointed by the minister on the recommendation of the board, as the ARA's chief executive officer. The CG effectively serves at the pleasure of the minister, who can remove him for malfeasance, incapacitation, or "any other sufficient cause." In the original statute the CG was "subject to the general supervision and control of the Board," though this phrase was deleted in the reform of the statute in $1998 .^{71}$ The CG actively works with the MOF on a regular basis and the link between the CG and the MOF seems in practice to be more important than the relationship between the CG and the board. The position of CG, however, is clearly subordinated to the minister, to the extent that major decisions have to be cleared by the minister, who has an informal veto over URA actions.

The South African ARA uses a weak version of the board of directors model. SARS' board, in fact, is purely advisory. The board consists of up to eight members named by the minister, up to two senior SARS employees named by the commissioner, and the commissioner himself. The minister also appoints the chairperson from among the members already named. The members serve a maximum term of five years, which is renewable. The minister may terminate a member's term "for a sufficient reason." A provision in the SARS act also requires the board to "inform the minister of any advice it gives to the commissioner." ${ }^{72}$

In practice both SARS senior managers and private sector observers acknowledge that the board has played a very limited role, which seems to have decreased over time. Some private sector representatives of peak organizations confessed ignorance not only of the board's membership but also of the board's role in the management of SARS. The board has played, however, a very limited role in the management of SARS through its standing committees, principally the audit and remunerations committees. The audit committee reviews quarterly reports from the internal audit unit while the remuneration committee provides advice on remuneration policies for senior managers. Still, as a result of the minor role played by the advisory board thus far, its usefulness has been called into question and its future is under review.

Mexico is sui generis among the Latin American ARAs as it is the only one to use a board of directors instead of a strong superintendent. In Mexico the SAT's board of directors (junta de gobierno) is composed of the following members: the minister of finance, two representatives from the ministry as designated by the minister, the president of the SAT, and two representatives from the SAT designated by the president. Given that all board members are from the MOF and the SAT, there is no space on the board for extra-governmental participation. In fact, the composition of the board is more akin to a technical/advisory board than an executive one.

The SAT law endows the board of directors with all important decision making authority, and guarantees the minister ultimate control over the board, thus clearly subordinating the SAT to ministerial control. In fact in practice the board has not played a very important role in either the management of SAT or in tax policy making. This has happened for two related reasons. First, given the closed composition of the board (top management of the MOF and SAT), the board does not offer much beyond what top management already has to offer (and many of them meet formally and informally outside of formal board meetings). Second, given the minister's complete control, the board has become somewhat superfluous. The board met infrequently during the first few years of the SAT's existence and key decisions were taken by the undersecretary for revenue and the minister without the formal consent of the board. Given the fact that the ministry has ultimate control of the SAT, the board has been seen as weak and ineffective, which has resulted in its being bypassed by informal decision making mechanisms.

\section{Indeed, there has been confusion about how to provide autonomy from the} government while also ensuring accountability to the government at the same time. The result has been the creation of boards of directors that are pulled in different directions by

\footnotetext{
${ }^{70}$ Interview, 7/18/01, Kampala, Uganda.

${ }^{71}$ URA Statute, 1991, Section 10 (2).

72 SARS Act, 1997, Part Three, Section 13 (2d).
} 
poorly designed governance mechanisms. Rather, I would argue, it makes more sense to grant the board a modicum of autonomy and to build in accountability mechanisms in the relationships between the board and the MOF, the monitoring agencies of the executive, and the legislature (accountability mechanisms are addressed below). The four suggestions outlined above would reduce MOF control over ARA boards, thus providing for greater autonomy.

In contrast to the African cases, the Latin American models have relied more on superintendents than boards of directors. Both Peru and Venezuela use superintendents, or CEOs, though Venezuela's revenue authority is characterized by a weak corporate governance mechanism.

SENIAT is managed by the superintendent and the adjunct superintendent, both of whom are named and removed by the minister of finance. Granting the minister the authority to name and remove the superintendent has clearly subordinated the ARA to the minister. In Venezuela the minister has used his authority to force his positions on the superintendent and has removed the superintendent for differences of opinion. In fact the average term of a superintendent has been merely 10.5 months over the period 19942000, with a take over of SENIAT by the MOF in late 1999 (that is, the post of superintendent remained vacant as direct control was exercised from the MOF). After the initial periods of reform (at the start of both the Caldera and Chávez administrations) the minister has had complete control over the superintendent, obviating in large measure the autonomy of the authority. In the Venezuelan system there are few effective checks on the minister's control over SENIAT, which means in practice that the ARA must depend on the goodwill and support of the MOF to carry out a reform agenda.

Peru's SUNAT is unique among the African and Latin American cases with respect to its high level of autonomy. SUNAT's superintendent is named and removed by the president of the republic, on the suggestion of the minister of finance with the approval of the council of ministers. Initially, the minister of finance had no say in the naming of the superintendent in practice (the first two superintendents were named by the president without the consultation of the minister). The average term served by SUNAT's superintendents was 1.8 years over the period 1991-2000 (excluding the tumultuous end of the Fujimori administration). 
The naming of the superintendent by the president, as the law provides, is a mechanism that has increased the autonomy of the ARA. However, providing the MOF with advise and consent powers has reduced the ARA's autonomy on some occasions. Depending on the relationship between the president and the minister, the minister may play more or less of a role in decisions about the superintendent and his tenure. In Peru the minister came to gain effective control over the nomination and removal process, thereby subordinating governance of SUNAT to the MOF, which was not necessarily a positive development.

The Latin American cases are all characterized by corporate governance mechanisms that feature strong MOF control, ranging from the MOF's outright dominance of the ARA's in Mexico and Venezuela to the more subtle influence of the MOF in Peru's ARA. In both the Mexican and Venezuelan cases the ARA's autonomy is quite limited in the area of corporate governance. This means that the ARAs have had to rely on the goodwill of the MOF, which was less forthcoming in the Mexican than the Venezuelan case. In the Venezuelan case a reform-minded minister of finance enabled the SENIAT experiment to take off in an impressive manner. The experiment was cut short less than two years later with the arrival of a new minister, however. In Peru the appointment mechanism of the superintendent requires the input of the minister, which has meant that as the interest of the president waned the influence of the minister grew. This again subjects the ARA to the goodwill of the MOF and is likely to weaken agency autonomy.

In practice the SARS commissioner is more like the Latin American superintendent, that is, a powerful CEO. The commissioner is appointed by the minister after consulting with both the cabinet and advisory board. The commissioner's term, which is renewable, cannot exceed five years. The first commissioner, who was the previous commissioner of income tax, was closely involved in the ARA reform. Given that the SARS act limits the authority of the commissioner vis-à-vis the minister, the fact that the current commissioner has been quite powerful must mean that some of his authority derives from his relationship with the minister as well as the general disposition 
of the minister toward the ARA. ${ }^{73}$ The concern is that the SARS corporate governance arrangement might operate very differently with a different set of actors. That is, the autonomy of the ARA is less institutionalized than in other cases and depends a great deal on individuals.

Though the Peru case demonstrates that the superintendent model can yield positive results, there is an argument to be made that the board of directors variant is preferable to the superintendent variant for a number of reasons. First, the superintendent model vests enormous power in a single individual, while the board model provides for a separation of power between the board and the CEO. Second, the board may provide for greater accountability, as it is charged with supervising the ARA's CEO directly. Third, the board can serve as a bulwark to protect the ARA from negative political interference.

Corporate Governance Issue 5: For greater autonomy and accountability, the board of directors model is preferred to the superintendent model.

This section has tackled the thorny question of ARA corporate governance and, based on the case studies, argues that the key design issue is fashioning a governance mechanism that yields some degree of autonomy. Whether the board of directors or superintendent model is used, if the ARA is subject to MOF control, autonomy will be quite limited in practice. The cases show that it is important not to confuse autonomy and accountability in the design of the governance structure. Rather, autonomy and accountability should be built into the governance structure separately. Trying to build both autonomy and accountability into the same design features muddles the governance mechanism.

\section{Funding Mechanisms and Budget Formulation}

The design of funding mechanisms for semi-autonomous ARAs centers on two key issues: (1) whether funding is automatically earmarked for the authority; and (2) whether funds are directly retained by the ARA (see Table 7).

Table 7. Funding Mechanism

SOURCES OF INCOME TRANSFER OF FUNDS

${ }^{73}$ The relationship between the MOF and SARS is quite close at present (2001); the SARS executive committee meets bi-monthly with the minister. 


\begin{tabular}{|c|c|c|}
\hline \multicolumn{3}{|c|}{ AFRICA } \\
\hline KRA & $\begin{array}{l}\text { - } 1.5 \% \text { of estimated collections } \\
\text { - } 3 \% \text { of the difference between actual and } \\
\text { estimated collections } \\
\text { - } \text { Maximum limit: } 2 \% \text { of collections } \\
\text { - } 1.5 \% \text { of collections done for other } \\
\text { organizations }\end{array}$ & $\begin{array}{l}\text { - Direct and indirect tax funds released } \\
\text { by treasury } \\
\text { - Direct retention of } 1.5 \% \text { of collections } \\
\text { done for other organizations }\end{array}$ \\
\hline SARS & - Parliamentary appropriation & - Funds released by ministry \\
\hline URA & - Parliamentary appropriation & - Funds released by ministry \\
\hline \multicolumn{3}{|c|}{ LATIN AMERICA } \\
\hline SAT & $\begin{array}{l}\text { - Congressional appropriations } \\
\text { - Additional resources based on agency's } \\
\text { efficiency and productivity }\end{array}$ & - Funds released by ministry \\
\hline SENIAT & $\begin{array}{l}\text { - Between } 3 \% \text { and } 5 \% \text { of non-petroleum } \\
\text { tax collections, as determined by the } \\
\text { president of the republic }\end{array}$ & - Funds released by ministry \\
\hline SUNAT & $\begin{array}{l}\text { - } \quad 2 \% \text { of tax collections } \\
-\quad 25 \% \text { of property auctions } \\
\text { - } \quad 0.2 \% \text { of non-treasury revenues }\end{array}$ & $\begin{array}{l}\text { - Funds retained (deposited directly) by } \\
\text { SUNAT }\end{array}$ \\
\hline
\end{tabular}

Source: ARA laws, acts, and decrees.

Of the Latin American cases SUNAT's financing mechanism is the most autonomous. The Venezuelan and Mexican revenue authorities, on the other hand, have much weaker funding mechanisms (see Table 7). SENIAT is supposed to be financed by "between $3 \%$ and $5 \%$ of non-petroleum taxes" it collects. The president of the republic is responsible for determining the percentage on an annual basis. In fact, SENIAT has not received more than $2 \%$ of collections. The SAT is financed by a hybrid mechanism in which normal congressional appropriations are supposed to be supplemented by additional resources based on its "productivity and efficiency." The additional resources, which have not been provided, are supposed to be used for improving infrastructure, improving taxpayer services, modernizing its processes, and to fund the Fiscal Career Service. $^{74}$

This paper argues for a fixed percentage based funding mechanism (based on actual revenues) on two counts: substituting for dysfunctional PEM systems and providing stronger incentives for collection (see Box 3 for a full discussion based on existing models). Clearly, the PEM substitution argument only makes sense if the PEM system is indeed dysfunctional. In that case, the percentage-based funding mechanism

\footnotetext{
${ }^{74}$ The URA and SARS have traditional parliamentary appropriations-based budgets.
} 
could help insulate the ARA from poor public expenditure management. This in turn would help to stabilize revenue collections, which would feed back greater stability into the PEM cycle.

Funding Issue 1: A fixed percentage-based funding mechanism, coupled with other design features, can provide greater operational autonomy, and, if properly linked to a staff performance bonuses, can enhance incentives for increasing collections.

\section{Box 3. The Percentage-Based Funding Mechanism: Insights from Peru and Kenya}

The percentage-based funding mechanism is one in which some fixed or variable percentage of funds is automatically earmarked for the authority ex ante. The theory behind the percentage-based funding mechanism is two-fold. First, proponents argue that the mechanism insulates ARAs from the vagaries of poor PEM processes by legally guaranteeing them a share of revenues, thus providing for greater budgetary stability. In countries in which budget execution does not closely correspond to approved budget allocations, and in which resources are not released in a timely or predictable manner, the percentage-based funding mechanism is thought to provide agencies with greater budgetary certainty and thus reliability. Based on its projected collections, the ARA would know exactly how much it would receive. The only uncertainty in its budget would be fluctuations in revenues. An important source of fluctuations-in-year resource reallocation by the treasury-would cease to be a problem. In fact, the cases show that in countries with inadequate PEM systems, the percentage-based mechanism fares no better than the traditional legislative appropriations method. The percentage mechanism cannot deliver resource predictability on its own.

The second reason given for the mechanism is that giving ARAs a percentage of the revenues they collect strengthens their incentives to boost collections. Assessing the validity of this argument requires a more thorough discussion. The cases serve to illustrate the key issues. In the simplest case, exemplified by Peru, a fixed two percent of actual collections is earmarked for the authority (according to the SUNAT law). A variant on this basic case employs a dual percentage-based mechanism, in which the base budget is equal to a fixed percentage of revenues and an additional performance-based component is added if collections exceed the estimated target. This variant is exemplified by the Kenyan case, in which the base budget is equal to $1.5 \%$ of estimated revenues and the performance component is calculated as three percent of the difference between actual and estimated collections (subject to a total maximum of two percent).

The two prototypical cases are shown graphically in Figure 2, which highlights the two main differences between the mechanisms. In the Kenyan case the fact that the base percentage is a function of estimated revenues assures the KRA of a fixed amount of income, irrespective of collections. Consequently, if collections were less than the estimated amount, the KRA's budget would remain constant, whether the gap were one percent or ten. On the other hand, for every increment in collections over the estimate, KRA would be rewarded with an additional three percent of the difference. Peru's authority, on the contrary, is not guaranteed any base budget but it is rewarded two percent of every increment in collections.

Peru's mechanism would seem to be superior to Kenya's for two reasons. First, and most importantly, defining the performance component as a function of estimated revenues places a great deal of importance on the quality of the estimation. In some sense the ARA would benefit or suffer as a result of measurement error. More problematic, however, is the possibility that such a formula would give both the ARA and the MOF incentives to behave strategically by setting revenue estimates to maximize budgets. This is complicated by the fact that the ARA usually plays an important role in the revenue estimation process. ${ }^{75}$ Moreover, the situation is characterized by asymmetric information, as the ARA has information

\footnotetext{
${ }^{75}$ Indeed, in one of the cases investigated the MOF complained that the ARA for strategic reasons routinely withheld information needed to make accurate revenue estimates, thus placing the MOF at a disadvantage.
} 
about individual taxpayers (investment plans, for example) that the MOF does not have. In a word, such a formula creates a conflict of interest for the ARA.

Secondly, the Peruvian funding mechanism provides consistent incentives to increase collections over the entire range of revenues. The Kenyan mechanism provides no incentives over a certain range (from zero to the estimated revenues), but then provides stronger incentives beyond that (and up to a maximum). The Kenyan model has the potential to induce distortions in the ARA incentive scheme, providing incentives that are too weak at the low end of collections and incentives that are too strong at the high end. The advantage of the Peruvian model is that it provides stable incentives on every incremental amount of collections. Moreover, and perhaps most importantly, it is administratively much simpler, as it is not subject to strategic manipulation.

Critics of the Peruvian variant of the percentage-based mechanism could point out that it is riskier for the tax agency on the grounds that a sudden decrease in revenues could destabilize the organization. Revenue shortfall due to some catastrophe (for example, a natural disaster) or significant reductions in certain commodity prices could indeed have a major impact on the agency's budget. In the event of a severe shock, the government would have to intervene, either to modify the tax system or provide additional revenues (for salaries, say) to the tax agency. ${ }^{76}$ These cases, however, would be quite rare.

A further criticism of any percentage-based funding mechanism is that it subjects the ARA to forces beyond its control, whether positive or negative. Given that tax agency efforts only determine a limited share of revenues collected, the agency could experience shortfalls or windfalls through no fault or merit of its own, as is the case in traditional appropriations-based budgeting. This problem could be somewhat mitigated by allowing the ARA to carry over unspent funds from year to year, thereby providing for income smoothing and encouraging the judicious use of resources. To the extent that the mechanism actually worked by providing greater incentives to increase collections, the undue portion of funds accruing to the ARA could be seen as the cost in some sense of establishing the incentive system.

The strongest criticism of the mechanism could come from the organizational economics school. The argument might be that a percentage-based funding mechanism like the Peruvian or Kenyan ones might provide incentives to the top management to increase collections, but it does not necessarily follow that these incentives would flow down to the staff. The reasoning is that if individual staff remuneration were not linked directly to collections, then staff would simply not have greater incentives to collect. Even if individual remuneration were linked to collections, it would be difficult to evaluate the performance of individual employees in light of their contribution to greater collections. This measurement problem would create room for shirking as some would undoubtedly free ride on the efforts of others, which would create additional incentive problems for the good performers. ${ }^{77}$

The organizational economics argument makes clear that linking ARA funding with staff remuneration is critical for enhancing incentives. A funding mechanism unlinked to staff remuneration in some way would be inefficient and, at worst, irrelevant. Senior management should have to take responsibility for rewarding staff based on good performance. Prescribing specific mechanisms for rewarding good performance in the ARA statute is unnecessary; rather, these decisions should be taken by senior management and the board on an annual basis. This would give them the flexibility to reward staff based on some type of administratively-appropriate performance evaluation system.

However, the case studies show that an additional feature-direct retention of funds - can have a major impact at the operational level. That is, the fixed-percentage mechanism by itself is not sufficient to guarantee actual allocation of resources to the ARA, as the cases of Kenya and Venezuela show. Given a fixed percentage mechanism based on actual collections, direct retention of funds by the ARA would be the most efficient way to support successful implementation, as the Peruvian case shows. The

\footnotetext{
${ }^{76}$ For example, in the wake of the Asian financial crisis, the Malaysian government suspended the income tax for one year.

${ }^{77}$ See Gary Miller (1992) for these types of arguments.
} 
ARA would simply retain its percentage of collections before transferring the difference to the treasury. Experience shows, moreover, that the percentage based funding mechanism is much less likely to work when the funds must still be parceled out by treasury; poor PEM systems have a record of undermining special funding mechanisms.

Indeed, the record shows that percentage-based funding mechanisms without the direct deposit feature have performed poorly. The KRA financing mechanism, for example, is percentage-based with a special provision for performance bonuses (see Table 7). In practice the KRA has received less than the statutorily-required $1.5 \%$ and has not received any performance bonuses. From 1995-2000 the KRA received an average of $1.2 \%$ of total estimated revenues. Including the foregone performance bonuses, by 2000 the treasury owed KRA the equivalent of $1.62 \%$ of total revenues in 1999/2000, that is, more than its annual budget (approximately Kshs. 2.7 billion).

Funding Issue 2: Direct retention of funds by ARAs can help mitigate the negative impacts of operating in a dysfunctional PEM system.

ARAs have also shown themselves to be entrepreneurial in reaching for additional taxes and fees to collect. For example, after signing an agreement with the Peruvian Social Security Institute, SUNAT collects social security fees and receives $2 \%$ of those collections. As of 2001 SARS is also collecting the Skills Development Levy on behalf of the Department of Labor and is authorized to retain two percent of collections to cover its costs. In the case of SARS, the percentage-based funding mechanism is used in addition to the traditional parliamentary appropriations method. The most important nontax revenue collected by the KRA is the road maintenance levy, of which the KRA retains $1.5 \%$ directly before transferring the difference to the treasury.

ARAs have also been granted varying control over their own budget formulation. In Africa budget formulation in many cases is a matter managed by the ARA board and its management. In the case of the KRA it is the board of directors that approves the allocation of the budget (within the aggregate limit set by the MOF, since the funding mechanism has been inoperable); the MOF plays no formal role. The KRA's budget is included as a line item in the MOF's budget in the MTEF. The KRA thus has a good deal of operational autonomy in budget formulation. Similarly, the URA, once an aggregate budget ceiling is set, has autonomy to allocate its resources internally, with the nominal 
approval of the board. As part of the MTEF SARS prepares a draft budget plus outer year projections, dividing its estimates into a baseline (based on the previous year) and new initiatives. The MOF makes the decision and informs the SARS of its aggregate budget ceiling for the coming fiscal year. The minister does have the discretion, however, to adjust SARS's appropriations during the year. SARS is authorized to alter in-year allocations as necessary without the approval of the MOF. SARS is not, however, authorized to retain funds beyond the fiscal year, unless authorized by the minister.

In Latin America budgetary autonomy varies considerably from case to case. The budget of the SAT must be approved by its board of directors, which means that the ministry maintains ultimate control on budgetary matters. In addition SENIAT's budget must be approved by the MOF. The SAT and SENIAT are controlled not only in terms of the total amount of their budgets but also the allocation of expenditures across general categories, thus limiting their autonomy.

SUNAT has more budgetary autonomy. SUNAT's budget is a direct function of the amount of taxes collected and SUNAT has complete autonomy with respect to budget formulation. SUNAT's budget is reviewed, however, by the Office of State Institutions and Organizations (OIOE), though only in terms of whether the budget is consistent with the government's overall macroeconomic goals. On occasion, the OIOE has asked SUNAT to reduce its overall budget by a certain percentage, the same one applied throughout the entire public sector. ${ }^{78}$ SUNAT must also send a copy of its budget to the legislature. The OIOE's oversight role thus provides for greater accountability without compromising SUNAT's autonomy.

Budget Management Issue: Revenue authority autonomy is strengthened by control over budget formulation, subject to approval either by the board of directors or an appropriate oversight agency.

Funding mechanisms and budgetary control are essential ingredients for making successful ARAs. In particular, the cases show that a percentage-based funding mechanism needs to have a direct retention feature in order for the funding mechanism to be meaningful in the context of a dysfunctional PEM system. Budget allocation

\footnotetext{
${ }^{78}$ SUNAT, in practice, has frequently reduced its budget by less than requested. OIOE does require SUNAT to account every trimester for differences in spending per category (using a fifteen category system) if actual expenditures vary by $5 \%$ or more from programmed expenditures.
} 
autonomy, subject to review by boards of directors or other appropriate oversight agencies, is also important for making autonomy effective at the managerial level.

\section{Personnel Systems}

Unlike the controversy that surrounds the corporate governance and funding mechanisms, the design of autonomous personnel systems are considerably more straightforward. The main issue is the extent of the ARA's autonomy to craft a personnel system independent of the civil service (see Table 8). In some cases, namely Kenya and Peru, the ARA is nearly independent of the civil service, at which point the main constraint to reform becomes the agency's budget. In other cases the authority's personnel system must comply with certain civil service regulations. If the goal of an autonomous personnel system is to allow the agency the flexibility necessary to attract and retain the number and quality of professionals necessary for improving performance, the cases suggest that a good deal of autonomy from the civil service is necessary to make this a reality.

Table 8. Personnel Systems

\begin{tabular}{|c|c|c|c|c|}
\hline & $\begin{array}{l}\text { PERSONNEL } \\
\text { POLICY UNIT }\end{array}$ & $\begin{array}{c}\text { LEGAL } \\
\text { FOUNDATION }\end{array}$ & $\begin{array}{l}\text { NON-SYSTEM } \\
\text { EMPLOYEES? }\end{array}$ & $\begin{array}{c}\text { RANGE OF } \\
\text { AUTONOMY }\end{array}$ \\
\hline \multicolumn{5}{|c|}{ AFRICA } \\
\hline KRA & $\begin{array}{l}\text { Board Staff } \\
\text { Committee and } \\
\text { management's } \\
\text { Appointments, } \\
\text { Promotions, and } \\
\text { Disciplinary } \\
\text { Committee }\end{array}$ & $\begin{array}{ll}\text { - } & \text { Board } \\
\text { regulations }\end{array}$ & $\begin{array}{l}\text { - Only CG (in that } \\
\text { he is appointed } \\
\text { by MOF) }\end{array}$ & 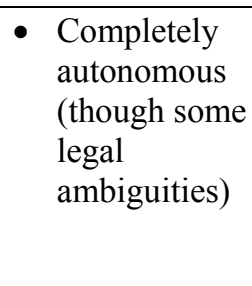 \\
\hline SARS & $\begin{array}{l}\text { - Human } \\
\text { Resources } \\
\text { Department }\end{array}$ & $\begin{array}{l}\text { Regulations } \\
\text { established by } \\
\text { commissioner } \\
\text { after collective } \\
\text { bargaining with } \\
\text { unions and } \\
\text { approval of the } \\
\text { MOF }\end{array}$ & 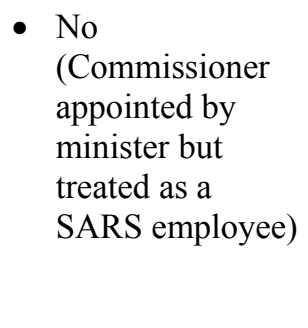 & $\begin{array}{l}\text { - Semi- } \\
\text { autonomous }\end{array}$ \\
\hline URA & $\begin{array}{l}\text { Board of } \\
\text { directors, } \\
\text { management } \\
\text { executive } \\
\text { committee, and } \\
\text { human resources } \\
\text { department }\end{array}$ & 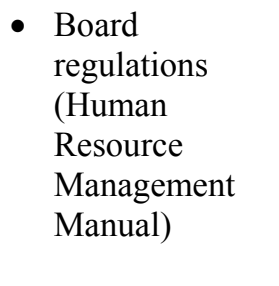 & $\begin{array}{l}\text { - Only CG (in that } \\
\text { he is appointed } \\
\text { by MOF) } \\
\text { - Some ambiguity } \\
\text { concerning } \\
\text { senior } \\
\text { management }\end{array}$ & $\begin{array}{l}\text { - Semi- } \\
\text { autonomous } \\
\text { (though some } \\
\text { ambiguities) }\end{array}$ \\
\hline
\end{tabular}




\begin{tabular}{|c|c|c|c|c|}
\hline \multicolumn{5}{|c|}{ LATIN AMERICA } \\
\hline SAT & $\begin{array}{l}\text { - Fiscal Career } \\
\text { Service } \\
\text { Commission }\end{array}$ & $\begin{array}{l}\text { Fiscal Career } \\
\text { Service } \\
\text { (regulations } \\
\text { issued by board } \\
\text { of directors) }\end{array}$ & $\begin{array}{l}\text { - Yes (percentage } \\
\text { undetermined) }\end{array}$ & $\begin{array}{l}\text { Board must have } \\
\text { decisions } \\
\text { approved by } \\
\text { MOF }\end{array}$ \\
\hline SENIAT & $\begin{array}{l}\text { - Human Resource } \\
\text { Department }\end{array}$ & $\begin{array}{l}\text { - Professional } \\
\text { Human Resource } \\
\text { System } \\
\text { (presidential } \\
\text { decree) }\end{array}$ & $\begin{array}{l}\text { - Yes (only } \\
\text { superintendent } \\
\text { and adjunct } \\
\text { superintendent) }\end{array}$ & $\begin{array}{l}\text { - Completely } \\
\text { autonomous } \\
\text { (initially, though } \\
\text { eroded over } \\
\text { time) }\end{array}$ \\
\hline SUNAT & $\begin{array}{l}\text { - Human Resource } \\
\text { Department and } \\
\text { Institute for Tax } \\
\text { Administration }\end{array}$ & $\begin{array}{l}\text { - Internal } \\
\text { regulations } \\
\text { (issued by } \\
\text { presidential } \\
\text { decree) }\end{array}$ & $\begin{array}{l}\text { - Yes (less than } \\
3 \% \text { of total staff) }\end{array}$ & $\begin{array}{l}\text { - Completely } \\
\text { autonomous }\end{array}$ \\
\hline
\end{tabular}

Source: ARA laws, acts, and decrees.

In the case of the KRA, the CG is authorized to appoint all staff members, except the commissioners of customs and excise, income, and value added taxes, who are appointed by the board. The board has established a Staff Committee, composed of the chairperson, three other board members, the CG, and the chief human resources and legal officers. It is the role of the committee to approve all hiring decisions for senior management positions. The KRA's Code of Conduct is the principal instrument guiding staff behavior and spelling out the procedures for handling disciplinary matters.

The terms and conditions of employment are determined by the board through its Staff Committee, which, overall, has played a major role in the development of the KRA personnel system. The KRA board is empowered to determine the salary structure and benefits package for agency personnel (the foundation for this aspect of autonomy is the KRA's exemption from the State Corporations Act).

The nature of the KRA's personnel autonomy, in spite of the apparent clarity of the KRA act, has not been crystal clear in practice: there have been cases in which the Public Service Commission has infringed on the KRA's autonomy. During the retrenchment exercise, for example, the commission took legal action against the KRA over the program (though the matter was subsequently resolved). The commission also issued a circular in 2001 on harmonizing housing allowances in the public sector, which seemed to apply to the KRA, in spite of the KRA's exemption from the State Corporations Act. Whether the commission will insist on the applicability of the policy to 
the KRA, as well as the KRA's position if the commission does insist, remains to be seen.

The foundation of the URA's personnel system is established in the (revised) statute. With the exception of the CG, all other management personnel, representing about seven percent of total staff, are appointed by the board, which also establishes the terms and conditions of all staff members. Contrary to the statute, URA officials report that in practice it is the minister of finance who actually recommends the appointment of the commissioners (and has informal veto power). In one case the minister allegedly also fired a commissioner and a deputy commissioner in 1997, in clear contravention of the legal procedures, which give this authority to the board. ${ }^{79}$

The URA's system is based on its Human Resource Management Manual, which addresses issues of recruitment and selection, appointments, promotion, employment conditions, compensation, allowances, training, and performance reviews. The manual is a comprehensive set of merit-based rules and procedures. The problem is that the Management Disciplinary Committee does not always follow or apply the rules as set out in the manual. Given the intervention of the MOF in personnel matters and the weakness of the board (the reformed board has not established a staff committee), there is no system to hold management accountable to the authority's personnel policy. Moreover, according to high level management, in spite of the authority's establishment control system, the total number of staff and their deployment were not rationalized in practice due to undue extraneous influences seeping into the personnel system. ${ }^{80}$

The URA has also had mounting problems situating its semi-autonomous personnel system in the context of the government-wide civil service. Several personnel issues have created intra-governmental disputes. ${ }^{81}$ The URA's personnel system is being

\footnotetext{
${ }^{79}$ Below level six (representing about $93 \%$ of total staff), staff are appointed by the management executive committee (composed of the CG and all commissioners) on the recommendation of the interviewing committees, which are coordinated by the board secretary and the human resources department.

${ }^{80}$ Interview, 7/11/01, Kampala, Uganda.

${ }^{81}$ URA's right to have a longer probationary period than that allowed by civil service regulations has been challenged successfully in court. The two year period, which URA used to monitor and screen employees, will have to be reduced to six months. There is also ambiguity about the URA's retirement age (55), which differs from that of the civil service (60). An additional lawsuit is underway over the URA's policy of not having to offer a reason for termination of employment (the URA takes this position due to the difficulties of proving suspected corruption).
} 
eroded by court challenges and new civil service regulations. It would seem that the authority's autonomy in the personnel sphere is limited at best.

In the case of South Africa, SARS was granted a good deal of autonomy over personnel management and used its autonomy over the past several years to modernize its systems. SARS's management determined the terms and conditions of employment after collective bargaining ${ }^{82}$ with the recognized trade unions and approval by the minister. Staff were recruited through a meritocratic evaluation process managed by the human resources department with final input from the hiring manager. Higher level staff had to be approved by the commissioner ${ }^{83}$ and general managers were appointed directly by the commissioner after undergoing an evaluation process. Many of the SARS's general managers, who form the executive committee together with the commissioner, were appointed on fixed contracts.

SARS personnel system had not been subject to challenge by the government's civil service commission, and so did not have the problem of erosion over time like the other African cases. SARS, by nature of its design, however, must subject its personnel policy to review by the MOF, which has resulted in at least one instance of disagreement over pay policy. It is not clear that micromanagement of tax administrators' salaries by the MOF added any value.

SUNAT has the most control over its personnel policy as compared with the other ARAs. President Fujimori had granted SUNAT the authority (by issuing a separate decree based on a legislative enabling law) to adopt a non-public sector personnel regime. SUNAT has the authority to appoint and remove its employees without the need to consult with any other public sector entity. SUNAT also has the ability to set its own salary structure, the only limitation being its budget. SUNAT could not, however, set salaries that exceed the maximum amount set by the OIOE, though in practice this did not seem to be a binding constraint.

SUNAT's superintendent has the authority to name and remove all managerial level functionaries in the organization, including the adjunct superintendent. The positions under the direct control of the superintendent account for less than $3 \%$ of the

\footnotetext{
${ }^{82}$ About $80 \%$ of SARS staff belong to one of two unions.

${ }^{83}$ This measure was introduced after concerns about nepotism surfaced in the organization.
} 
total staff (at 2000 levels). The remaining staff are selected according to meritocratic procedures. SUNAT's personnel system, which is administered by its human resources department, has been quite resistant to political interference. ${ }^{84}$ In addition, SUNAT's management has been very stable over time with few changes made as a result of the arrival of a new superintendent.

In Mexico the SAT's Fiscal Career Service (SFC) was voluntary for current SAT employees and mandatory only for new employees. Moreover, the SFC only applied to a certain percentage of employees; that is, there was still a category of "freely designated" employees, who did not have to fulfill any SFC requirements, and were named by the president or the board. This category included not only high level managers, but also specialists and technical professionals. The SFC was thus of limited applicability to the organization as a whole.

The SFC is operated by a commission of SAT officials, which is composed of the president, a technical secretary, and the heads of all administrative departments and units. The SFC, created as part of the SAT law, was further developed in the SAT's internal regulation, issued by the board of directors. The design of the SFC is not completely under the control of the SAT, however. The undersecretary for expenditure and the civil service unit must approve any changes in salary structures and personnel regulations. Thus the SAT has limited legal autonomy to design its own personnel system.

SENIAT also initially created an agency-based personnel system: the Professional Human Resources System (PHRS). The PHRS, which applied to all SENIAT functionaries, except the superintendent and adjunct superintendent, provided for a meritocratic, professional system, covering recruitment, salaries, promotion, development, and dismissal. The system allowed SENIAT to set its own salary scales and provided performance bonuses. It also provided a trial period for new employees and prohibited those with criminal backgrounds from seeking employment in the agency. However, SENIAT functionaries are still considered public sector employees and with regard to issues not explicitly regulated by the PHRS, public administrative law applies.

\footnotetext{
${ }^{84}$ There were allegations, however, that National Intelligence Service (SIN) agents infiltrated SUNAT during the last few years of the Fujimori administration.
} 
The PHRS is operated informally by the superintendent, the human resource department, and the heads of the regional offices, though there is no official operating body. Within the regulations of the PHRS, the superintendent was authorized to name all normative level functionaries and the managers of the regional offices, who in turn were authorized to appoint the functionaries in their regions.

The PHRS guaranteed SENIAT complete personnel policy autonomy. Though SENIAT took some cues from the public administration personnel system (for example, the PHRS is required to offer benefit packages at least as good as those in the public administration), is has no obligation to follow public sector regulations. The PHRS is also the most detailed and explicit of the agency-based civil service systems. ${ }^{85}$

In practice, however, the PHRS has not been consistently implemented. In spite of a promising start, the PHRS has not continued to guide decision making on personnel issues in SENIAT. Implementation of the system has depended on the disposition of the minister and the superintendent, who have not always utilized the system. Nonmeritocratic designation of employees seemed to be the internal norm in SENIAT during the late 1990s. Serious budget constraints also undermined the institutionalization of the PHRS.

Personnel Issue: To safeguard autonomy the ARA personnel system should be: (a) exempted in the ARA founding law from government-wide civil service regulations, and (b) developed and regulated exclusively by the board of directors.

The cases show that ARAs exempted from government-wide civil service regulations had greater autonomy to develop personnel systems that met their needs. In addition, these ARAs were better placed to resist attempts by other government actors to encroach on their autonomy. A comparison of the Latin American and African cases shows that boards of directors can play a useful role in developing the agency's personnel system over time. The Venezuelan case shows that no matter how well-designed the personnel system may be, if its integrity is not protected, it can easily be undermined.

\section{$\underline{\text { Procurement }}$}

\footnotetext{
${ }^{85}$ The PHRS statute was issued as a presidential decree.
} 
Much like the personnel issue, the central question regarding ARA procurement autonomy is the ability of the agency to institute a flexible yet accountable procurement system that allows for improved performance. The country cases suggest that without the autonomy to design their own systems, central government procurement systems impede effective management and do not necessarily provide adequate safeguards.

An important element of KRA's autonomy has been its ability to design its own procurement system. The fundamental characteristic of the system, which was developed by the board's finance committee (and its sub-committee on procurement), is managerial flexibility. Broadly, the CG is authorized to spend up to Kshs. one million. Expenditures between Kshs. one and six million must be approved by the board's Finance Committee, while anything greater must be approved by the full board. The KRA's procurement regulations, which have been widely regarded as successful in promoting flexibility and accountability, were later drawn on by the government when it undertook procurement reform. The KRA's procurement system thus supported the government's reform program, and may even have helped catalyze the wider reform effort. This example of a positive spillover of KRA autonomy to the wider public sector should not be overlooked as it demonstrates the potential of one "pocket of reform" to support other reform efforts.

The URA has less autonomy in matters of procurement. As of 1998 the government established a new procurement system in which all requests greater than US\$ 50,000 must be approved by a government procurement management contractor, which also charges a user fee to the requesting agency. URA was made subject to this mechanism as well, though from 1991-1998 it had autonomy to make its own procurement decisions. For purchases below the threshold the management tender committee, composed of commissioners, has to authorize purchases. For amounts greater than US\$ 30,000, the board must also give its approval. The encroachment on the URA's procurement autonomy is another example of legal ambiguities giving way to greater central government control.

SARS inherited the central government procurement system when it became autonomous in 1997. SARS established its own tender board and adopted a slightly streamlined version of the government's regulations. Because the tender rules and procedures have not been redesigned, SARS still suffers from delays and inflexibilities in 
contracting. The problem is felt most acutely in the area of IT, whose managers believe there is "huge room for improvement." $\$ 86$

Neither SENIAT, nor the SAT had any differentiated procurement powers; each was subject to the standard procurement regulations of the public sector. SUNAT, on the other hand, while usually subject to standard procurement regulations, was given strategic reprieves from such regulations on certain occasions. For instance, in the first years of the reform SUNAT was authorized by presidential decree to make several important investments in buildings and IT systems without being bound by governmentwide procurement regulations. The decree gave SUNAT a limited timeframe in which to make the investments. Once the decree expired, SUNAT had to resume compliance with the standard procedures. SENIAT relied on periodic negotiations with the government comptroller to ease procurement regulations regarding large scale investments.

Procurement Issue: Empowering ARAs to design their own procurement systems, under the supervision of boards of directors and other relevant oversight agencies, makes autonomy more meaningful at the operational level.

The consistently most limited dimension of autonomy across the four cases is procurement policy. At a minimum, the ARA design removed a layer of the procurement hierarchy. Though ARAs are still bound by the public sector procurement regulations, they generally do not need approval from the ministry of finance to make purchases.

\section{Accountability Mechanisms}

Formal accountability mechanisms vary significantly from case to case, perhaps because they are part of the system of corporate governance, around which there has been much debate and ambiguity. What is non-controversial is the need to balance autonomy with effective accountability. How exactly that is done, however, is open for discussion, as the cases show. Several of the cases, notably Kenya, offer potential models for other countries to emulate.

One important feature characteristic of the African and the Mexican case is the establishment of a direct link to the legislature. This is important not only to ensure ARA accountability to the government, but to ensure that other government entities are also

\footnotetext{
${ }^{86}$ Interview, SARS, 7/20/01.
} 
accountable in relation to the ARA. Mexico's SAT is the only ARA in Latin America that has a direct accountability link to the legislature. Every trimester the SAT is required to present a report to congress on its performance. In addition during the first six weeks of the year the president of the SAT is required to send a report (approved by the board) to congress on the programs to be implemented, the budget, and the previous year's collections.

Accountability Issue 1: To ensure fiduciary and democratic accountability, formal, regularized linkages between the ARA and the legislature should be established.

Overall, the African cases have more advanced accountability systems than the Latin American cases. The Kenyan case, which is exemplary, is characterized by several overlapping accountability mechanisms. ${ }^{87}$ The first is the traditional internal audit unit, which is charged with performing quarterly audits and presenting the results to the CG. The second accountability link is between the CG and the board. The CG is required to present the quarterly audits to the board, as well as to the CAG, who forms the third link. In addition the CAG is charged with auditing the annual accounts of the authority. The fourth layer of accountability is between the CG and the MOF. The CG must present the authority's financial statements, performance indicators, and annual report both to the board and the MOF. The minister establishes a fifth accountability link with the National Assembly by furnishing it with copies of the KRA's annual report and the CAG's report. A sixth link is established by the Kenya Anti-Corruption Authority (KACA), which has audited the KRA in order to make recommendations on reducing potential avenues for corruption. ${ }^{88}$ Lastly, the KRA must publish its audited accounts in the public record and make them available to the public.

The KRA is characterized by the most layered accountability system of the cases examined. The board and MOF form the first layer of oversight, which is the most active. The second layer is formed by the CAG and KACA, while the third is formed by the National Assembly and the public. In the first six years of KRA's existence the accountability mechanisms have worked fairly well. Of course the quality of the oversight depends not on the KRA, but on the capacity of the overseers.

\footnotetext{
${ }^{87}$ The Ugandan case is similar on paper, but seems to function less well in practice.

${ }^{88}$ The KACA was later declared unconstitutional.
} 
SARS, perhaps because it has less autonomy, has fewer accountability relationships with the central government. As in the other cases SARS has an internal audit division that reports directly to the commissioner. In SARS case the internal audit unit also has direct access to the chairperson of the advisory board and submits quarterly reports to the SARS audit committee. Unlike in Kenya and Uganda, the ARA has no formal reporting relationship to the board, though it does report to the MOF. Each year SARS must submit a performance and financial report to the minister, who in turn must submit it to the parliament (as well as the National Council of Provinces). The Public Finance Management Act (PFMA) also requires that SARS submit its business plan to the parliament. In addition to the accountability relationship between SARS and the MOF, the AG must also audit SARS's accounts on an annual basis.

The Latin American cases are characterized by fewer formal accountability mechanisms. Since SENIAT is so closely under the supervision of the ministry, the MOF actually functions as the direct overseer. SUNAT has few formal reporting relationships with other government entities, though it falls within the sector of the MOF. SUNAT must report on its budget to the ministry, which also undertakes periodic evaluations of SUNAT.

Accountability Issue 2: Taking accountability seriously means crafting a set of accountability linkages between the ARA and responsible oversight bodies, including the board of directors, the ministry of finance, the comptroller/auditor general, and parliament.

The cases show, thus far, that accountability has not suffered as a result of autonomy. In fact, it is not clear that instances of malfeasance and corruption are worse in ARAs than they are in other public sector organizations. At the same time it is not apparent that ARAs are more accountable and less corrupt, either. Anecdotal evidence indicates that in the more autonomous and more performance-oriented ARAs-Peru, Kenya, and South Africa-corruption has decreased and accountability has improved, but it is difficult to provide hard evidence for such assertions. Some ARAs have quite well designed accountability mechanisms, which could easily be replicated in other countries. This section provides an analysis of the key accountability features that should 
be built in to ARAs to ensure that they are responsive to their political principals, while at the same time ensuring that accountability does not unduly infringe on agency autonomy.

\section{$\underline{\text { Conclusion }}$}

The cases show that the level of agency autonomy varies considerably from country to country. Though this section does not construct a formal ranking of autonomy, the relatively more autonomous revenue authorities seem to be Peru and Kenya while the less autonomous ones are Mexico and Venezuela. South Africa and Uganda would fall between these two sets on an autonomy scale.

This section has made a number of recommendations, based on good practice, as well as problematic examples, from the cases, about how to design ARAs so that they have the level of autonomy needed to function more effectively. While detailed recommendations need not be repeated, three central lessons emerge from the analysis. First, for autonomy to be meaningful, the ARA should have some operational distance from the MOF. Simply put, there is no need for the MOF to micromanage ARA affairs. Moreover, if the MOF is highly politicized, linking the ARA too closely to the MOF could undermine the reform.

Second, ARA designs are often convoluted in the way they build accountability into the system. Many designs mistakenly try to limit autonomy with the intention of increasing accountability. These designs muddle the managerial waters and, in fact, reduce both autonomy and accountability. Rather, separate design features should tackle the issues of accountability and autonomy. Accountability should be ensured through a series of linkages between the ARA and the executive and legislative branches, as well as its board of directors (think of a "checks and balances" approach ensuring accountability).

Third, the board of directors model, as opposed to the superintendent model, promises greater benefits in terms of agency management and accountability. Boards, properly designed, can play an important role in advising the revenue authority on key issues such as personnel policy and overall business strategy. Boards can also insulate ARAs from political pressure and can serve as a check on their autonomy. These general 
findings, as well as the specific recommendations in the text, should serve to improve the design of the next generation of ARAs.

\section{CONCLUSION}

This paper has taken up critical questions and controversies about the design and performance of semi-autonomous revenue authorities in Africa and Latin America. The paper has analyzed the link between autonomy and performance, arguing that if one compares the pre- and post-reform state of affairs in these cases, the ARA demonstrates improvement in most cases along most dimensions of performance. The cases show that managers used their autonomy to implement reforms that enabled them to improve organizational management, and thus improve agency performance. It is important to note that most of these organizational reforms - critical to improving performancecould not have been undertaken without the autonomy afforded by the ARA design. Moreover, the paper finds that the relatively more autonomous revenue authorities (Peru, Kenya, and South Africa) have been more adept at increasing performance than the less autonomous ones (Uganda, Mexico, and Venezuela). Thus, autonomy seems to matter, and more autonomy seems to matter more.

The paper also analyzes organization design issues in detail from a practical perspective and provides guidelines for improving the next generation of ARA reforms. Three principal lessons emerge: (1) ARAs need a certain operational distance from MOFs for autonomy to be meaningful; (2) separate design features should be used to build autonomy and enhance accountability; and (3) the board of directors model affords greater governance benefits as compared to the CEO model.

The cases also suggest that what has mattered most for improved performance is personnel reform. That is, in the Peruvian, South African, and Kenyan cases, a combination of retrenchment, pay reform, and a focus on personnel integrity seem to have had the greatest impact on performance. Though other factors were important, especially modes of corporate governance, personnel reform seems to have mattered in a foundational way. The extent to which ARAs were able to undertake personnel reform, of course, is a function of their level of autonomy, not only along the personnel dimension, but along the corporate governance and funding dimensions, as radical personnel reform 
is both unlikely when political pressure can easily be put on the ARA and costly, necessitating access to resources that might not be forthcoming if the ARA does not have access to a modicum of financial autonomy.

All of this is not to say, however, that autonomy is the only factor that determines ARA performance. It would be foolish not to recognize the importance of professional, capable managers in these success stories. Indeed, autonomy without a professional management team would produce little of value. Nor is it to say that politics does not matter. Clearly, political support is what allowed for the ARA reform in the first place and what allows for sustainable performance. It is, however, to suggest that autonomy is a key (necessary?) ingredient for the rapid and radical improvement of tax administration in developing countries.

In conclusion, the paper has argued that the semi-autonomous revenue authority model, properly designed, can serve to improve tax administration in developing countries in a rapid and comprehensive manner. Politicians and tax administrators in some countries would do well to consider establishing ARAs. The question becomes: in which countries do ARAs make sense? The section concludes by posing a number of framework questions, the answer to which would guide the decision making process:

- Human Resources: Does the civil service system (including salary levels) allow for the recruitment and retention of specialized professionals in the tax agency? Is the civil service system flexible enough to provide for the development of specialized skills within the agency?

$\circ$ Public expenditure and financial management (PEFM): Is the PEFM system sufficiently developed to allow for the execution of spending (as approved in the budget) in a predictable and timely fashion? Are budgeted resources likely to be adequate given resource scarcity?

- Political influence and corruption: Is the public administration robust enough to deal effectively with undue political influence and corruption in the tax agency?

- Procurement: Are procurement practices adequate for ensuring accountability and flexibility at the agency level? 
To the extent that the answers to these questions are in the negative, the case for an ARA becomes more compelling, because it is in these contexts that ARAs hold the most promise of making tax administration more effective, efficient, and fair. ${ }^{89}$

${ }^{89}$ The political logic of ARA reform is analyzed in Taliercio (2000). 


\section{BIBLIOGRAPHY}

Adamolekum, Ladipo and Ousman Jah. N.D. "Enclave Approach to Tax and Customs Administration in Africa: Three Country Studies." Manuscript.

Bahl, Roy and Jorge Martínez-Vazquez. 1992. "The Nexus of Tax Administration and Tax Policy in Jamaica and Guatemala." In Improving Tax Administration in Developing Countries, edited by Richard M. Bird and Milka Casanegra de Jantscher. Washington, D.C.: International Monetary Fund.

Bird, Richard M. and Milka Casanegra de Jantscher, eds. 1992. Improving Tax Administration in Developing Countries. Washington, D.C.: International Monetary Fund.

Devas, Nick, Simon Delay, and Michael Hubbard. 2001. "Revenue Authorities: Are they the Right Vehicle for Improved Tax Administration?" Public Administration and Development, 21: 211-222.

Durand, Francisco. 2002. "Desarrollo institucional de SUNAT: Factores de éxito y fracaso." Aportes al Debate, No. 6. Friedrich Ebert Stiftung.

Durand, Francisco and Rosemary Thorp. 1998. "Reforming the State: A Study of the Peruvian Tax Reform.” Oxford Development Studies, Vol. 26, No. 2: 133-151.

Fjeldstad, Odd-Helge. 2002. "Controlling Fiscal Corruption: Lessons from the Tanzania Revenue Authority." Manuscript.

Fjeldstad, Odd-Helge and Joseph Semboja. 2001. "Why People Pay Taxes: The Case of the Development Levy in Tanzania." World Development, Vol. 29, No. 12: 2059-2074.

Hlophe, Dumisani and Steven Friedman. 2002. "...And Their Hearts and Minds Will Follow...' Tax Collection, Authority and Legitimacy in Democratic South Africa." IDS Bulletin, Vol. 33, No. 3: 67-76.

International Monetary Fund. 2003. Fiscal Adjustment in IMF-Supported Programs. Independent Evaluation Office. Washington, DC.

James, Simon and Ian G. Wallschutzky. 1995. "The Shape of Future Tax Administrations.” International Bureau of Fiscal Documentation, May: 210-218.

Jenkins, Glenn P. 1994. "Modernization of Tax Administration: Revenue Boards and Privatization as Instruments of Change." Bulletin for International Fiscal Documentation, Vol. 48: 75-81.

Mann, Arthur. 2004. "Are Semi-Autonomous Revenue Authorities the Answer to Tax Administration Problems in Developing Countries? A Practical Guide," Ms. 
Olsson, Gunnar and Frank Waltersson. N.D. "Performance Measurement in Tax Administrations." Manuscript.

Serra, Pablo. 2003. "Measuring the Performance of Chile's Tax Administration." National Tax Journal, Vol. LVI, No. 2: 373-383.

Silvani, Carlos. 1992. “Improving Tax Compliance.” In Improving Tax Administration in Developing Countries, edited by Richard M. Bird and Milka Casanegra de Jantscher. Washington, D.C.: International Monetary Fund.

Silvani, Carlos and Katherine Baer. 1997. Designing a Tax Administration Reform Strategy: Experiences and Guidelines. Fiscal Affairs Department, International Monetary Fund: Washington, DC.

Taliercio, Robert R. 2000. Administrative Reform as Credible Commitment: The Design, Performance, and Sustainability of Semi-Autonomous Revenue Authorities in Latin America. Unpublished doctoral dissertation, Harvard University, Cambridge, MA. . 2004a. "Administrative Reform as Credible Commitment: The Impact of Autonomy on Revenue Authority Performance in Latin America." World Development, Vol. 32, No. 2: 213-232.

. 2004b. "Raising Revenues or Raising Hackles?: The Problem of Sustainability of Semi-Autonomous Tax Agencies in Developing Countries.” Ms.

Tanzi, Vito. 1995. Taxation in an Integrating World. Washington, D.C.: The Brookings Institution.

Terkper, Seth. 2003. "Decade of Tax Administration Reforms in Sub-Saharan Africa: Overview of Organization." Manuscript.

Verhoest, Koen, B. Guy Peters, Geert Bouckaert, and Bram Verschuere. 2004. "The Study of Organisational Autonomy: A Conceptual Review," Public Administration and Development, Vol. 24: 101-118. 
Figure 2

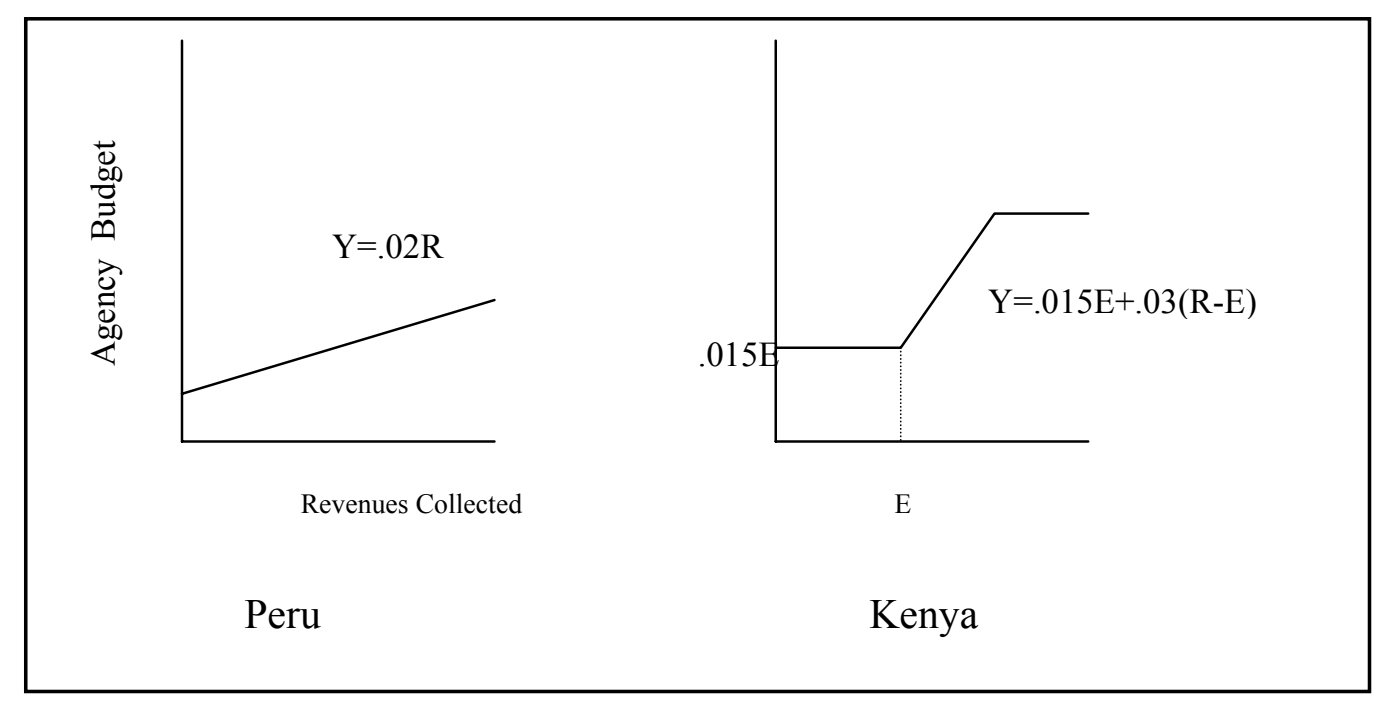

